\title{
Decadal regime shift linkage between global marine fish landings and atmospheric planetary wave forcing
}

\author{
A. M. Powell Jr. ${ }^{1}$ and J. $\mathrm{Xu}^{2}$ \\ ${ }^{1}$ Center for Satellite Applications and Research (STAR), NOAA/NESDIS College Park, Maryland, USA \\ ${ }^{2}$ Environmental Science and Technology Center College of Science, George Mason University, Fairfax, USA
}

Correspondence to: A. M. Powell Jr. (al.powell@ noaa.gov)

Received: 26 June 2014 - Published in Earth Syst. Dynam. Discuss.: 7 August 2014

Revised: 2 February 2015 - Accepted: 3 March 2015 - Published: 2 April 2015

\begin{abstract}
This investigation focuses on a global forcing mechanism for decadal regime shifts and their subsequent impacts. The proposed global forcing mechanism is that the global atmospheric planetary waves can lead to changes in the global surface air-sea conditions and subsequently fishery changes. In this study, the five decadal regime shifts (1956-1957, 1964-1965, 1977-1978, 1988-1989, and 1998-1999) in the most recent 59year period (1950-2008) have been identified based on Student $t$ tests and their association with global marine ecosystem change has been discussed. Changes in the three major oceanic (Pacific, Atlantic, and Indian) ecosystems will be explored with the goal of demonstrating the linkage between stratospheric planetary waves and the ocean surface forcing that leads to fisheries impacts. The global forcing mechanism is described with a top-down approach to help the multidisciplinary audience follow the analysis. Following previous work, this analysis addresses how changes in the atmospheric planetary waves may influence the vertical wind structure, surface wind stress, and their connection with the global ocean ecosystems based on a coupling of the atmospheric regime shifts with the decadal regime shifts determined from marine life changes. The multiple decadal regime shifts related to changes in marine life are discussed using the United Nations Food and Agriculture Organization's (FAO) global fish capture data (catch/stock). Analyses are performed to demonstrate that examining the interactions between the atmosphere, ocean, and fisheries is a plausible approach to explaining decadal climate change in the global marine ecosystems and its impacts. The results show a consistent mechanism, ocean wind stress, responsible for marine shifts in the three major ocean basins. Changes in the planetary wave pattern affect the ocean wind stress patterns. A change in the ocean surface wind pattern from longwave (relatively smooth and less complex) to shorter-wave (more convoluted and more complex) ocean surface wind stress creates changes in global marine fisheries.
\end{abstract}

\section{Introduction}

The global marine ecosystems in the world's major oceans exhibit long-term variations in time resembling "regime shifts". A regime shift is a transition from one state to another, with the transition period being much shorter than the length of the individual epochs (Overland et al., 2008). Regime shifts are associated with large, abrupt, persistent changes in both atmospheric and oceanic conditions that may be especially pronounced in physical and biological variables. Generally, regime shifts have been found to have occurred in 1925, 1947, 1977, 1989, and 1998 (Mantua et al., 1997; Minobe, 1999; Beamish et al., 2004; King, 2005; Overland et al., 2008; Powell and Xu, 2011a). The 1976/77 regime shift is the most commonly identified shift in the literature currently and is often identified with high-amplitude changes in numerous atmospheric, oceanic, and biological measures cited in the literature (Ebbesmeyer et al., 1991; Minobe, 1997, 1999; Overland et al., 2008; Powell and Xu, 2012). A combination of atmospheric and oceanic forcing is thought to cause marine changes by affecting the physical ocean which impacts the ocean habitat or ecosystem. The purpose of this research is to determine whether a common 
global mechanism can be found consistent with the Chavez proposition (Chavez et al., 2003) that all the world's oceans and fisheries are affected in near synchrony by a simple and direct forcing that is similar in the different ocean basins. If a forcing can be identified, the regime shift strength and timing could be estimated and possibly forecast based on atmospheric, oceanic, and biological change. A regime shift forecast capability could provide decision makers with a significant tool for estimating ocean ecosystem impacts.

Regime shifts in fish populations are difficult to explain on the basis of biological relationships alone or fishing pressure (Chavez et al., 2003). Lehodey et al. (2006) stated that fish population variability is closely related to environmental variability. Based on the fishery landing data on Canada's Pacific coast, Beamish et al. (2004) pointed out that the fish catches were related to trends in the climate and ocean environment that could be considered associated with regime shifts. In recent years, numerous long-term changes in physical forcing have been observed at global, regional, and basin scales as a result of climate changes. In particular, the impacts of sea surface temperature (SST) on ocean wind stress and vice versa have been investigated due to their key effects on atmosphere-ocean interaction (Chelton et al., 2001). Impacts of various forcings on biological processes supporting fish production in marine ecosystems have already been observed and may be used as proxies to estimate further global climate change impacts. As an example, El Niño's wellknown wind direction impacts on upwelling/downwelling off South America's west coast results in periods of extremely good and extremely poor fishing conditions that have had severe economic consequences. The effects of El Niño are felt in areas outside the west coast of South America. Physical factors that could impact fish production include atmospheric circulation and oceanic environmental (wind stress patterns, upwelling/downwelling, water temperature, ocean currents, spawning temperatures, etc.) variability patterns (Roy and Reason, 2001; Sugimoto et al., 2001). All of these factors are affected by the ocean wind stress. Chavez et al. (2003) remarked that the mechanism(s) responsible for the abrupt regime shifts should be relatively direct and simple, similar in the different regions, and likely linked with large-scale atmospheric and oceanic forcing. In this research, the key issue is to assess global atmospheric planetary wave structures to identify regime shifts in terms of the global atmospheric forcing (wind stress) that have ocean impacts and marine impacts (changes in normalized fish landings). The goal is to develop a global regime concept to support an improved understanding of the near-synchronous marine changes in all the world's ocean basins. The variability of large marine populations and their associated ecosystems are likely impacted through global regime shift patterns or decadal climate change.

To detect regime shifts in the global marine environment, the United Nations Food and Agriculture Organization's (FAO) global fish capture (landings) data was used. The approach was to first detect the year(s) when regime shifts oc-

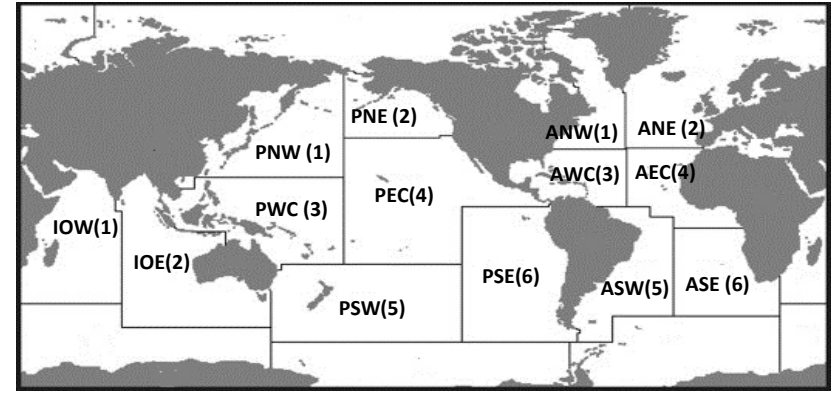

Figure 1. The Food and Agriculture Organization's (FAO) 14 sub-ocean regions for marine fish species landings in the $\mathrm{Pa}$ cific, Atlantic, and Indian oceans and the 9 groups of marine species tabulated - ocean sub-regions on grey shaded map: Pacific, Northwest (PNW); Pacific, Western Central (PWC); Pacific, Southwest (PSW); Pacific, Northeast (PNE); Pacific, Eastern Central (PEC); Pacific, Southeast (PSE); Atlantic, Northwest (ANW); Atlantic, Western Central (AWC); Atlantic, Southwest (ASW); Atlantic, Northeast (ANE); Atlantic, Eastern Central (AEC); Atlantic, Southeast(ASE); Indian Ocean, Eastern (IOE); Indian Ocean, Western (IOW). Nine FAO species groups: (1) Cod, Hakes, Haddocks (CHH), (2) Flounders, Halibut, Soles (FHS), (3) Herrings, Anchovies, Sardines (HAS), (4) Marine Fishes Not Identified (MFNI), (5) Miscellaneous Coastal Fishes (MCF), (6) Miscellaneous Demersal Fishes (MDF), (7) Miscellaneous Pelagic Fishes (MPF), (8) Sharks, Rays, Chimaeras (SRC), (9) Tunas, Bonitos, Billfishes (TBB). The codes used in the graphics of this paper represent the combination of the FAO geographical ocean sub-regions (shown in this figure) and the fish species categories are listed above (for example, PNW-CHH is the Pacific Northwest regions' Cod, Hakes, and Haddocks fish species group). The shortened combined codes (i.e., P21) used in the paper as the $x$ axis identifiers are described in Table A1 of the Appendix.

curred in the global fish capture statistics using the Student $t$ test. A comparison with the planetary wave index analysis was used to assess the likelihood the marine regime shifts were caused by global atmospheric forcing.

\section{Data}

The data used in this study include the FAO global statistics on fish capture production. The atmospheric temperature and geopotential height fields used for the planetary wave amplitude index are from the NCEP/NCAR reanalysis (19482008).

\subsection{FAO's fish capture data}

The FAO fish capture data is the only available data set on the global fish catch (Froese et al., 2012) and it is also the most broadly used and accepted database (M. Liddel, personal communication, 2014). The database provides a service to the community interested in fishery information although there have been questions about the data quality and its use 
in various applications (Watson and Pauly, 2001; Hilborn and Branch, 2013). Its extensive use has demonstrated the value of this data set for a wide variety of analyses. Over 600 articles from refereed journals have cited the database in the last 15 years. Many improvements have been made over time to make the database suitable for detailed analyses (Garibaldi, 2012). In addition, criticisms of the database or its applications have been addressed in refereed journals (Froese et al., 2012). The scientific community has made the best use of this unique data set to understand the impact on fisheries similar to the analysis accomplished in this paper. The annual series of capture production began in 1950. The data includes all quantities caught and landed for both food and feed purposes but excludes discards. Fish catches/landings are expressed in live weight which is the nominal weight of the aquatic organisms at the time of capture. According to the marine area where caught, capture production is also classified into 14 major marine fishing areas (Fig. 1) encompassing the waters of the Atlantic, Indian, and Pacific oceans. The fish landing data for the Antarctic and Arctic oceans with their adjacent seas (Fig. 1) are not included in this data and could be a source of bias. The FAO database contains the volume of aquatic species caught by country or area, by species, by FAO major fishing areas, and year for all commercial, industrial, recreational, and subsistence purposes. The 9 families of FAO marine fish species are listed in Fig. 1 along with a map of the 14 sub-regional data collection oceanic areas. To minimize the effect of episodic or exceptional events, similar to the processing used in the previous studies (DeYoung et al., 2004; Powell and Xu, 2013), this data undergoes normalization as described in the third paragraph of this section.

The authors address the use of fish catch data in this analysis. There are difficulties with using this data. It is clear that reporting procedures have resulted in under-reporting fish catch in some countries and over reporting in others, particularly China (Watson and Pauly, 2001). Policies and fishing rights changes in various regions of the world as well as changes in equipment can influence the catch statistics. In addition, catches can shift for many reasons including reclassifying the fish catch data categories. The adoption of marine protected areas and policies to improve protected/declining species seem to have positive impacts on the abundance of fish and potentially fish catch (Hilborn and Branch, 2013). The reliability and issues associated with the fish catch data comes from two articles Watson and Pauly (2001) and Hilborn and Branch (2013). Using the FAO fish catch data, Froese et al. (2012) showed explicitly that trends in catch data are not an artifact of the applied method and are consistent with trends in biomass data of fully assessed stocks.

The authors believe the information contained in previous articles discuss the basic issues with fish catch data. However, this is the only comprehensive global database (Froese et al., 2012) from which to draw upon actual measurements. For the purposes of this analysis, the FAO fish catch data is the most prominent and comprehensive fishery data set available to assess linkages between global physical environmental forcings and the biological impacts on the world's fisheries. By normalizing the data, in aggregate, it should reflect real changes in fish catch whether the fish migrated to alternative regions, the ocean ecosystems changed, or other factors such as changes in fishing equipment or fishing policies played a role in the fish catch changes. Because this research seeks to identify the physical coupling between the atmospheric forcing and the resultant impact on fisheries, it is thought to be highly unlikely that changes in fishing strategies and policies are likely to significantly affect five major marine regime shifts. In addition, the coupling of the marine regime shifts to atmospheric regimes shifts should provide significant evidence that the wind driven ocean circulations play a role in the synchronous changes in global fish populations that have been identified in the literature. All the fish landing data were normalized based on the available record from 1950 through 2008. This normalization suppresses biases due to under- and over-reporting of fish landings and provides a reasonable comparison of the marine system. The purpose of using this data is to demonstrate that changes in environmental forcings impact the world's oceans in a similar manner, but not necessarily impacting the same fish species group(s) in each region or ocean basin. For the purposes of this analysis, the authors think the data is sufficiently robust to make a determination about environmental impacts on fish species groups. Analyses of this type help the community understand the data and the potential impacts of factors that influence the statistics. In this study, the landing data provides insights into environmental impacts on the biological processes related to the world's fisheries.

\subsection{NCEP/NCAR reanalysis (NNR)}

The monthly NCEP/NCAR reanalysis with a $2.5^{\circ} \times 2.5^{\circ}$ grid resolution is used in the period of 1950-2008. It should be noted that the reanalysis period of 1958-1978 has no satellite data. The Television Infrared Observation Satellite (TIROS) Operational Vertical Sounder (TOVS) data includes the Microwave Sounding Unit (MSU), High Resolution Infrared Radiation Sounder (HIRS) and Stratospheric Sounding Units (SSU). The satellite information was not available for use in forecast models before the end of 1978; this is true for the atmospheric reanalysis used for this study. The Special Sensing Microwave/Imager (SSM/I) data was assimilated into the National Weather Service forecast system from 1993. The lack of satellite data in the early years could degrade the atmospheric analysis prior to the availability of the satellite data. The NNR temperature and geopotential height fields between 20 and $70 \mathrm{hPa}$ (stratosphere) were used in this study to identify atmospheric regime shifts and their vertical connectivity to the ocean surface since previous analyses indicated the strongest planetary waves were in the stratosphere (Powell and Xu, 2012). Selected atmospheric pressure levels between the stratosphere and the surface $(1000 \mathrm{hPa})$ were 


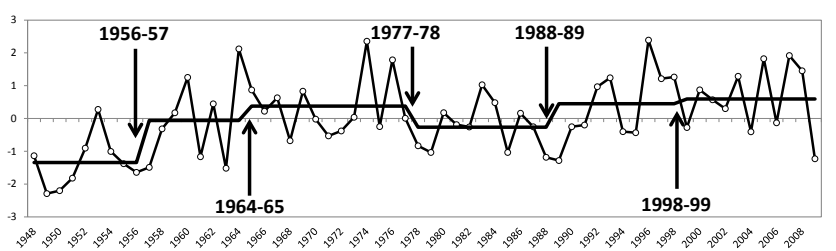

Figure 2. Normalized planetary wave amplitude index (PWAI) from 1948 to 2008 for $55-75^{\circ} \mathrm{N}$ and $70-20 \mathrm{hPa}$ with identified regime shift periods and approximate shift dates. Regime shifts are identified at 1956-1957, 1964-1965, 1977-1978, 1988-1989, and 1998-1999.

used to demonstrate the dynamic linkage between all levels of the atmosphere and the relationship with surface environmental conditions.

\section{Methodology}

\subsection{Normalization processing}

To make a comparison of the interannual and decadal variability for each individual parameter over the time series, each parameter $\left(x_{i}, i=1,2, \ldots N\right)$ must be normalized from the starting date to the end of the data set. The atmospheric data $(20-70 \mathrm{hPa})$ and each fish species group were first normalized using the calculation expressed as follows:

$\tilde{x}_{i}=\frac{x_{i}-\bar{x}}{\sigma}$,

where $\bar{x}=\frac{1}{N} \sum_{i=1}^{N} x_{i}$ and $\sigma=\sqrt{\frac{1}{N} \sum_{i=1}^{N}\left(x_{i}-\bar{x}\right)^{2}}$.

See Powell and Xu (2011b) for more details. This provided the ability to determine the regime shift periods using a consistent approach between dissimilar data sets.

\subsection{Fourier spectrum analysis}

The geopotential height, temperature, and wind fields from the NCEP-NCAR reanalysis were decomposed into Fourier harmonics, and the Fourier coefficients were used to recompose the temporal field for single zonal waves. Wavenumbers 1 through 6 are Fourier decomposed from the 59-year (1950-2008) data set. The geopotential height fields are consistent with the manner in which most meteorologists display weather patterns used in forecasting.

The height field anomalies were computed to highlight the changes in the global fields and to show the effect on the various levels of atmospheric low and high pressure systems. The height field anomalies across the multiple regime shifts will be discussed later in the paper.

\subsection{Identification of the regime shifts}

To identify the regime shifts, the atmospheric planetary wave amplitude index (PWAI; Powell and Xu, 2011b) established the atmospheric planetary wave strength which was shown to influence ocean forcing through surface wind stress (Powell and $\mathrm{Xu}, 2012$ ). The $55-75^{\circ} \mathrm{N}$ latitudes were used to identify mid-latitude forcing associated with global synoptic-scale changes in the wind and vertical wave propagation which was previously analyzed as strong in the region. The $90 \%$ confidence level was established for the running Student $t$ test decadal period comparisons and provided an assessment of the most confident regime shift dates. For this analysis, the regime shift test was completed using 5 years on either side of the running target year (an 11-year interval in total, so it is called the 11-year (decadal) running $t$ test in the following sections) to determine whether a significant regime shift on the decadal timescale had occurred. The most confident dates (positive or negative) are used as the dates of key atmospheric regime shifts. The planetary wave amplitude indices show regime shifts (Fig. 2) occurring at approximately 1956-1957, 1964-1965, 1977-1978, 1988-1989, and 19981999. The averaged values for each decadal period provide a way to assess the degree of the change across each shift and are shown in Fig. 2. It is worth noticing that the 1998-1999 regime shift does not clearly pass the significant $t$ test at the $90 \%$ confidence level, but the shift is consistent with previous studies (Overland et al., 2008; Powell and Xu, 2011a). Since atmospheric forcing of the ocean is thought to be a critical factor, the atmospheric regime shifts are matched with the effects of the ocean surface stress and marine changes via fish landings in the research analysis.

\subsection{Surface kinetic energy change with wavenumber}

To measure the spatial characteristics of the surface atmospheric circulation and its forcing, the kinetic energy (KE) in the atmospheric surface waves over each major ocean domain is calculated. The KE is expressed by $1 / 2\left(U^{2}(n)+\right.$ $\left.V^{2}(n)\right)$, where $n$ is the zonal wavenumber and $U$ and $V$ are the zonal and meridional wind components, respectively. The $\mathrm{KE}$ is assessed based on the wind anomalies associated with each ocean domain (Pacific, Atlantic, and Indian oceans).

\section{Results}

\subsection{Regime shifts from the global FAO fish landing}

The purpose of this section is to discuss the marine regime shifts identified in the global FAO fish landing data, indicating abrupt biological change, that can be associated with the atmospheric regime shifts. This begins the process of linking global biological change with physical changes in the ocean, ocean surface wind stress, and atmospheric forcing. To detect the potential global regime shifts, similar to the approach conducted in the determination of global planetary 
wave regime shifts (Powell and $\mathrm{Xu}, 2012$ ), the time series of marine landing data over each of the sub-regions were analyzed using the 11-year running Student $t$ test conducted on the normalized FAO fish landing data. The fish landing data included 9 fish species groups in 14 sub-regions (see Fig. 1 and Table A1 in the Appendix) over the Pacific, Indian, and Atlantic oceans. The analysis period is 59 years, from 1950 to 2008 .

Figure 3 shows the detrended time series and 11-year running $t$ test value for selected fish landings over the three ocean basins. The results clearly show that the year of regime shift occurrence depended on both the fish species group and sub-region. For example, the years of regime shift occurrence are identified (Fig. 3a) at 1966, 1977, 1987, and 2000 for the MDF fish species group (see Appendix A1 for definitions of the fish groups) over the western central Pacific Ocean (PWC), different from the years found (Fig. 3j; 1963, 1972, 1977, and 1988) for the MCF over the eastern central Atlantic Ocean (AEC). Regime shift transitions occur within a window of 2-3 years. The peak shift date within the transition window could come ahead or behind the central date during each decade. The individual fish species group graphics may appear to be inconsistent with the climate or ecosystem regime shifts found by previous studies from various data sets. In fact, each individual graph looks rather unique, although each identifies distinct regime shifts with some similar to and some different than other plots. This is likely due to the varying conditions in each region and the response of the various species to the changing conditions. These graphs were plotted for all 14 sub-regions with their 9 fish species categories for a total of $126(14 \times 9)$ regional fish species groups. However, when the statistical analysis for all nine fish species over the 14 sub-regions is analyzed, it shows a consistent result with the previous regime shift findings. By computing the frequency of occurrence of the various fish regime shifts for the Pacific, Atlantic, and Indian oceans, the temporal pattern of the most frequent regime shift occurrences matches closely with the regime shifts identified from the changing atmospheric patterns shown earlier.

Appendix Table A2 shows the year when a regime shift occurred in each decade. Based on the number of decadal regime shift occurrences collected in the running 2-year interval (consistent with the short transition time for a regime shift), the percentage of fish landing regime shift occurrences (Fig. 4) indicates the regime shifts exceeding the statistical significance test at the $90 \%$ confidence level are identified at 1955-1956, 1964-1965, 1977-1978, 1988-1989, and 19992000 in each decade over the Pacific Ocean (Fig. 4a). Similar shifts are observed within 1 or 2 years over the Atlantic Ocean (Fig. 4b), but two shifts at 1963-1964 and 1999-2000 satisfy the significance test at $85 \%$ confidence levels. Both the Atlantic and Pacific regime shift patterns are consistent. The fish landing regime shifts over the Indian Ocean show some different features from the other two ocean basins. Three regime shifts at 1957-1958, 1989-1990, and 1999-
2000 passed the significance test at $90 \%$ confidence level, and are consistent with those in the Atlantic and Pacific. The other three regime shifts are observed at 1969-1970, 19801981 , and 1995-1996 using the $85 \%$ confidence level. Overall, the results generally reproduced the five regime shifts from previous studies based on various data sets (Mantua et al., 1997; Minobe, 1999; Overland et al., 2008; Powell and $\mathrm{Xu}, 2011 \mathrm{a})$. However, it is worth noting that the regime shifts in the Indian Ocean are different from their counterparts in the Pacific and Atlantic oceans.

The analysis shown in Fig. 4 identifies similar abrupt shift periods (1955-1958, 1963-1965, 1976-1978, 1987-1990, 1998-2000) in the fish catch data as the atmospheric data (Fig. 2), suggesting a potential link between the atmospheric forcing and the impacts on the fish species. The different regimes shifts in the Indian Ocean suggest a second forcing mechanism unrelated or indirectly related to direct atmospheric forcing. Since the atmospheric analysis was based on middle- to high-latitude wind forcing patterns indicative of non-tropical wind conditions, it is possible the Indian Ocean (which is also bounded to the north and west by land masses), may not react completely in concert with the other ocean basins since it is a "tropical ocean". There is insufficient data to determine whether additional regime shifts exist from other forcings from the analysis technique applied. The remaining lesser shifts identified are substantially weaker and could be due to interannual variability or other factors and have been excluded from direct comparison.

The potential linkage between the five most frequent regime shifts identified in Fig. 4 from the fish landing data that correspond with the five abrupt shifts in the atmospheric planetary wave data (Fig. 2) will be described in the following paragraphs. It should be pointed out that the global fishery regime shifts produce a 15 to $25 \%$ change (Fig. 4 ) in the sub-region fish species across the regime shifts with lesser percentage changes likely due to interannual variability. In addition, the sub-region species are affected differently even within the same ocean basin. This suggests the regime shift forcing mechanism may have sub-regional effects and will be addressed in Sects. 6 and 7.

\subsection{Decadal shift in the stratospheric atmospheric planetary wave}

The purpose of this section is to discuss the causality of atmospheric regime shifts, primarily in the Earth's stratosphere, as they relate to the biological abrupt shifts of similar dates found in the FAO fish landing data. This begins the process of demonstrating the top-down linkage between abrupt atmospheric change leading to surface wind stress changes which have impacts on biological variability. This section discusses the global change in atmospheric state between the regime shifts at the strongest level identified in the atmospheric data $(50 \mathrm{hPa}$, located in the stratosphere). 

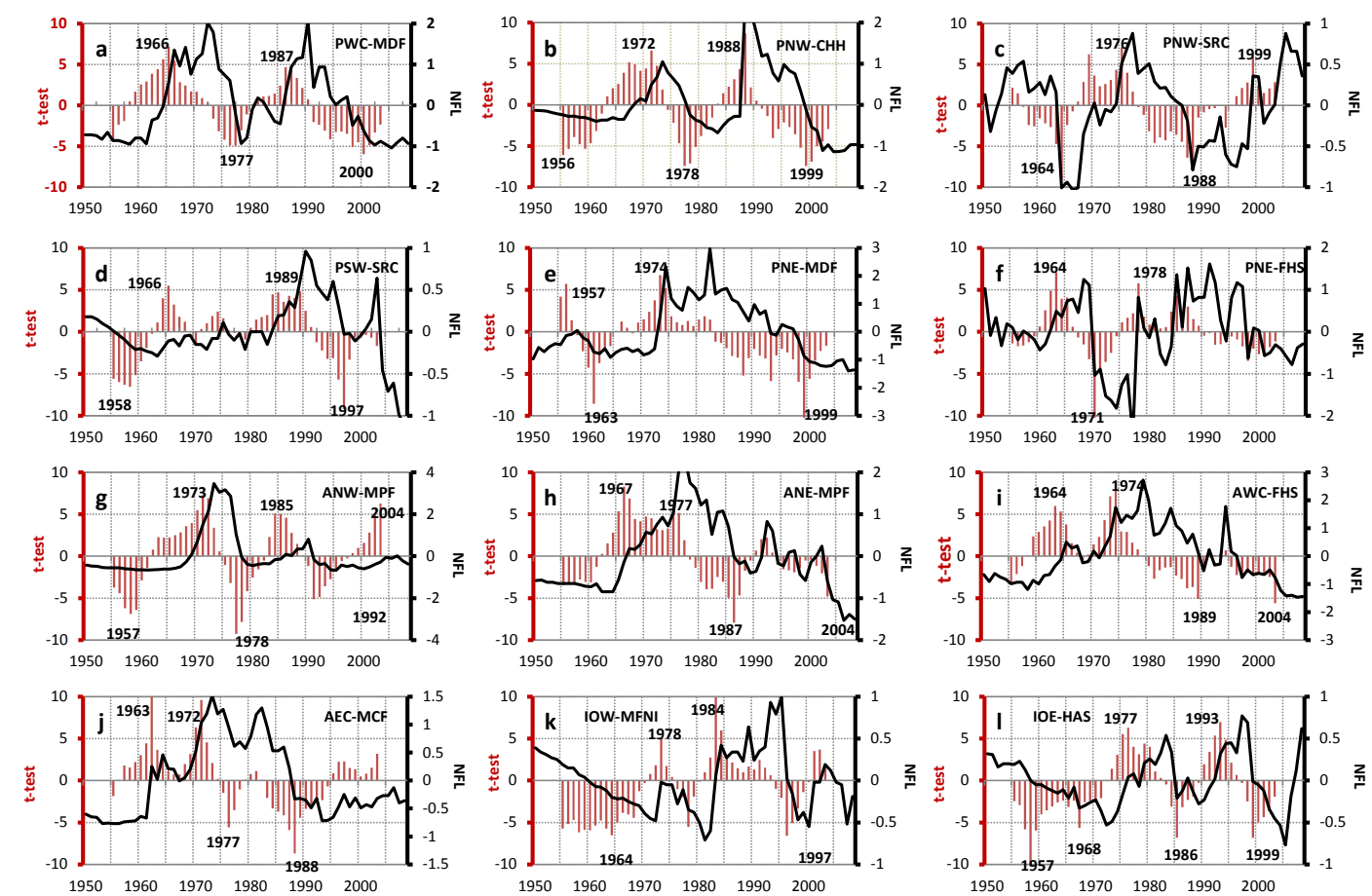

Figure 3. The detrended time series of the normalized fishery landing (NFL) with black curves over the three ocean basins (scaled on the right $y$ axis), the 11-year running $t$ test with red bar (scaled on the left $y$ axis). The number indicates the year when the regime shift happened, based on passing the significance test at the $90 \%$ confidence level. Each panel in this figure is the sample selected from the total 14 sub-regions and 9 species groups listed in Table 1A. Pacific Ocean: (a) PWC-MDF; (b) PNW-CHH; (c) PNW-SRC, (d) PSW-SRC; (e) PNE-MDF; (f) PNE-FHS. Atlantic Ocean: (g) ANW-MPF; (h) ANE-MPF; (i) AWC-FHS; (j) AEC-MCF. Indian Ocean: (k) IOW-MFNI; (l) IOE-HAS. The distributions of the other fish species over the other sub-regions are not shown here, but all regime shift years are listed in Table 2A.

In previous research, the changes in the atmospheric planetary wave pattern showed unique changes between the years with the strongest planetary waves and the weakest ones (Powell and Xu, 2011b). Also, the amplitudes of the planetary waves in the stratosphere seemed to be associated with ocean changes. Given the findings in the previous studies, an extension of this work investigated how the wave pattern changed across multiple regime shifts (Powell and $\mathrm{Xu}$, 2011a). The analysis was performed at the $50 \mathrm{hPa}$ level (in the stratosphere) where the effect appeared strongest (Powell and $\mathrm{Xu}, 2011 \mathrm{~b}$ ). The $50 \mathrm{hPa}$ level regime shift periods of 1948-1956, 1957-1964, 1965-1977, 1978-1988, 19891998, and 1999-2005 showed that the global atmospheric planetary wave pattern essentially shifted (changed phase or location) in each of the periods (Fig. 5). However, the method of transferring wave energy from the various levels in the atmosphere to the surface was not specifically addressed in the earlier Powell and $\mathrm{Xu}$ (2011a) analysis, but will be addressed in the following section.

Using the five regime shift dates (six regime intervals) identified in both atmospheric and fish landing data sets, a top down analysis was undertaken from the atmosphere to the ocean surface. The atmospheric wave pattern was analyzed to determine whether a cause-effect mechanism could be identified to explain the changes between the regime shift periods. Fourier analysis of wavenumbers 1 through 6 derived from the height fields of the NCEP-NCAR atmospheric reanalysis (NNR) shows the global wave pattern anomalies (Fig. 5). For the multidisciplinary audience, the patterns represent the significant features in the average northern hemispheric weather pattern for the identified periods. The colored (high pressure with clockwise wind circulation) and uncolored (low pressure with counter clockwise wind circulation) regions in Fig. 5 represent the changes in the strength and position of the dominant weather systems for the periods of interest. The closer the contours are together, the stronger the winds are. The planetary wave anomalies at $50 \mathrm{hPa}$ (in the stratosphere at approximately $20 \mathrm{~km}$ in height) are shown for each abrupt shift period: (a) 1948-1956, (b) 1957-1964, (c) 1965-1977, (d) 1978-1988, (e) 1989-1998, and (f) 19992005. From Powell and Xu (2012), it was shown that the strongest wave amplitudes occurred in the NNR between 20 and $70 \mathrm{hPa}$ with $50 \mathrm{hPa}$ typically among the strongest levels. In addition, the wavenumber 1 global atmospheric anomaly pattern tended to change state by approximately reversing positions between the high and low pressure height anomalies (Powell and Xu, 2011b). Since global atmospheric wavenumber 1 is the strongest (has the most energy) and has 


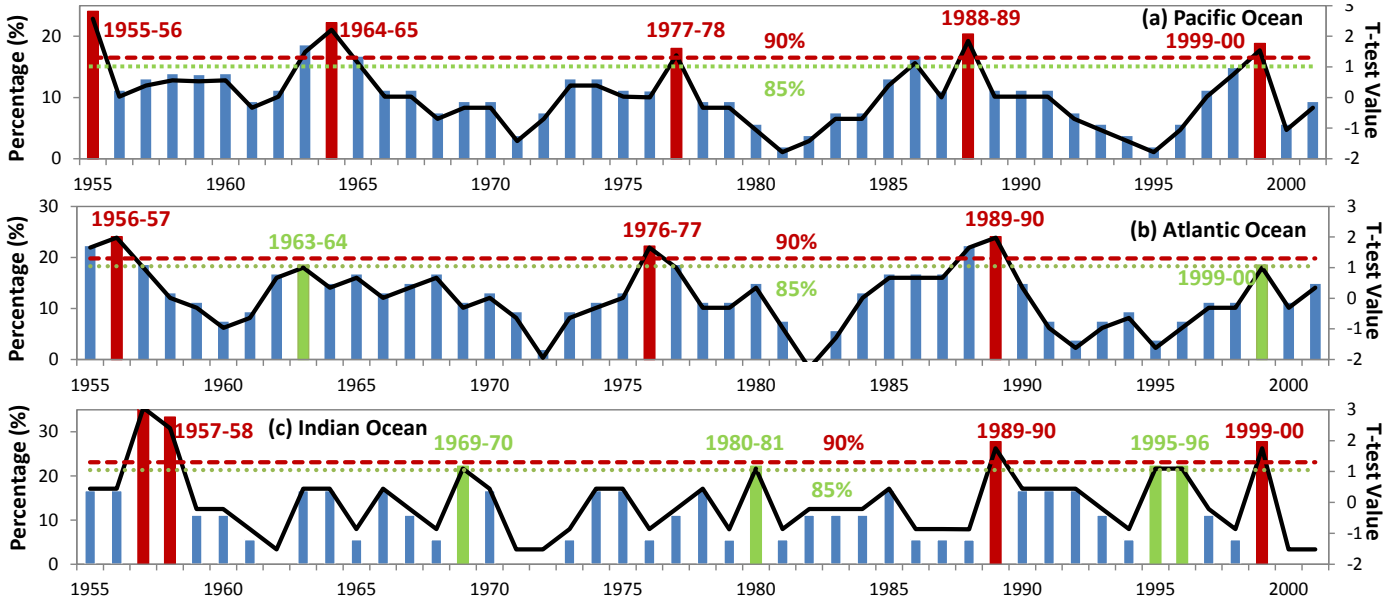

Figure 4. The rate of fish landing regime shift occurrence The percentage of fish landing regime shift occurrences (the bars; left $y$ axis) changes with time based on the statistical results of Table A2 in Appendix and Student $t$ test value (black curves line, right $y$ axis). The red dashed line indicates the threshold of statistical significance $t$ test at the $90 \%$ confidence level (right $y$ axis). The red dashed and dotted green lines indicate the statistical significance $t$ test thresholds at the $90 \%$ and $85 \%$ confidence levels (right $y-$ axis), respectively. The red or green bars indicate the maximum 2-year percentage of regime shift occurrences (passing either the 90 or $85 \%$ statistical significance threshold) in each decade for the (a) Pacific Ocean, (b) Atlantic Ocean, and (c) Indian Ocean. The rate calculation is according to total counts of regime shift occurrence during 2 continuous years, the approach is made as follows. For example, during the 10 years from 1971 to 1980 over the Pacific Ocean in Table A2, there are 7 sub-region/fish species showing the regime shift at year 1977 and 3 sub-region/fish species at year 1978, so there are 10 sub-region/fish species showing the shift in 1977-1978. The total sub-region/fish species is 54 (6 sub-regions $\times 9$ species $=54$ ) over the Pacific Ocean, so the rate of regime shift occurrence in 1977-78 is $10 / 54=18.5 \%$. The others were obtained in the same way.

ANOM 1948-56 (a)

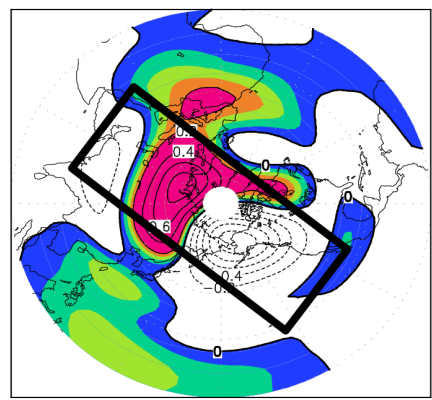

ANOM 1957-64 (b)

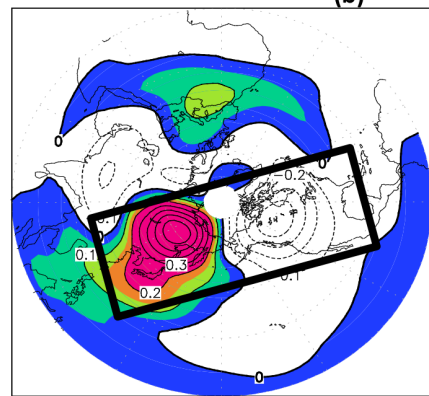

ANOM1965-77 (c)

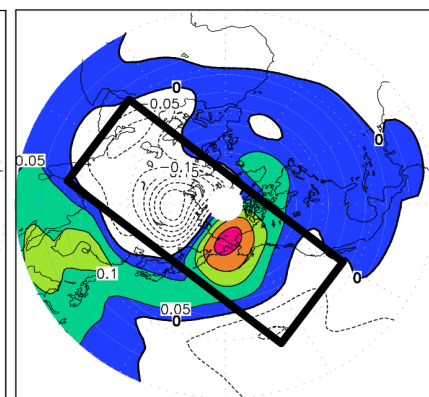

ANOM 1978-88(d)

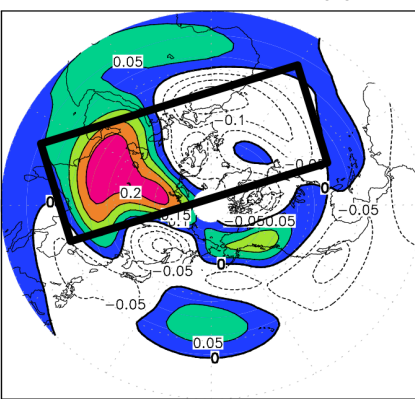

ANOM 1989-98 (e)

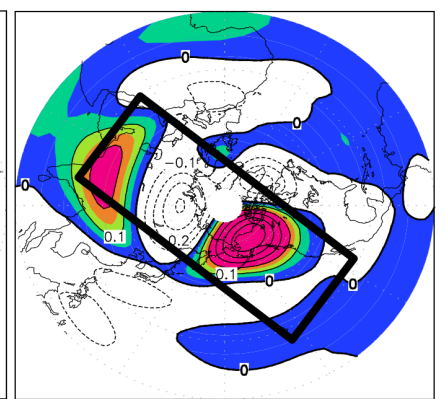

ANOM 1999-2005(f)

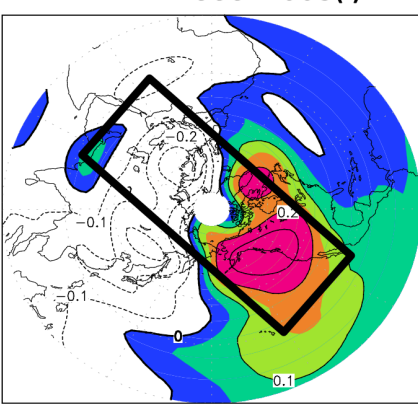

Figure 5. Reconstructed planetary wave pattern using geopotential height for wavenumbers $1-6$ at 50 hPa in the NCEP/NCAR reanalysis. Wave anomalies in the following regime shift periods: (a) 1948-1956; (b) 1957-1964; (c) 1965-1977; (d) 1978-1988; (e) 1989-1998; (f) 1999-2005. Units: gpm (geopotential height). Shaded areas indicate positive anomalies. Block boxes show positions of net large-scale features associated with the atmospheric regime shifts. 
two primary "lobes" that represent the primary atmospheric wave (represented by the red and white region combination approximately $180^{\circ}$ apart and outlined by the black boxes), its effects can be seen in each regime shift period's height anomaly pattern. The combined impacts of wavenumbers 1 through 6 are shown to demonstrate how the additional, but weaker, wavenumbers add complexity to the atmospheric forcing pattern while retaining the dominant wavenumber 1 pattern, although shifted in phase and amplitude.

Starting with the 1948-1956 period, the 1957-1965 pattern is shifted significantly when looking at the primary red (solid contours) and white shaded regions (dashed contours). Comparing the 1948-1956 pattern with each of the subsequent periods (1965-1977, 1978-1988, and 1989-1999) shows a significant shift or "reversal" of the global wave pattern anomalies from one period to the next. Only the last period representing 1999-2005 does not show a significant change in the pattern, but the pattern is weaker in terms of the anomaly magnitudes observed in the previous panel. Also, the 1999-2005 period may be too long since another regime shift was possibly identified in 2003 within the period of interest (Peterson et al., 2006; Hátún et al., 2009). Note the wave anomaly positions suggest that the continents or geography may play a key role in where the anomalies form, and is consistent with meteorological dynamics. However, additional study will be required to confirm this potential geographic association with the pattern and the regime shifts.

There are clear distinguishing shifts and changes in the atmospheric pattern in the stratosphere in Fig. 5. Since the wind patterns change in accordance with the shifts in atmospheric wave pattern, it is reasonable to assume the surface winds and ocean will show corresponding signs of change. The global wave pattern anomalies are indicative of wind changes throughout the depth of the atmosphere and the surface wind stress patterns should reflect any changes.

\subsection{Top-down connection from stratosphere through surface}

The purpose of this section is to relate global stratospheric planetary wave changes to surface wind stress via top-down or vertical forcing processes. To demonstrate a mechanism exists that can transfer substantial energy from the stratosphere to the troposphere (the lower atmosphere in contact with the Earth's surface) through planetary waves, the global height anomalies in the vertical were analyzed. The height anomalies indicate the vertical change in intensity and placement of the global low and high pressure systems which are the lobes of the planetary wave pattern. The wind and temperature gradients associated with high and low pressure systems require a dynamic process(es) to maintain continuity vertically in the atmosphere. The tilting of the systems with height is a recognized consequence among meteorologists of the atmospheric dynamics required to support these systems. Consequently, the investigation focused on large-scale plan- etary wave changes and their associated vertical adjustments in the height fields - used by meteorologists to assess the dynamic state of the atmosphere and make predictions.

The analysis in Fig. 6 was undertaken to demonstrate that dynamic changes in the vertical through the high and low pressure systems provide the surface wind forcing needed to modify the ocean's currents and subsequently impact marine ecosystems at the Earth's surface. The large-scale anomaly features seen in the stratosphere at the $50 \mathrm{hPa}$ level (and matching the positions of the large pressure systems shown in polar plots in Fig. 5) can be followed to the surface via the generally red and blue colored regions (Fig. 6) which typically weaken in amplitude as they approach the surface $(1000 \mathrm{hPa}$ level). These height anomalies are consistent with the physical structure and processes for high and low pressure systems that generate the world's daily weather as well. The critical impact of this vertical structure is that it communicates to the Earth's surface a wind forcing pattern that affects the oceans.

Globally, there are strong wind and height anomalous regions over the Pacific, Atlantic, and Indian oceans before and after each regime shift. However, a key difference is that the anomaly areas are basically out of phase indicating the global wave pattern has shifted, causing regional wind flow changes. For example, prior to the 1977-1978 regime shift, the strongest two "height anomaly columns" representing high and low pressure circulations are over central Asia (negative anomaly, blue) and the central Pacific (positive anomaly, green turning to red as one goes lower in height). After 1978, the strongest two "height columns" of high and low pressure are over central Asia (positive anomaly, red) and over the central Pacific (negative anomaly, blue). This is essentially a change of phase between the two periods for both the positions and amplitudes of the core wave pattern features. In addition, it is clear that the strongest anomaly patterns, both before and after the regime shift, are at the $50 \mathrm{hPa}$ level and generally decrease in strength as they approach the surface. The height anomaly changes span the stratosphere to the surface. In these anomaly fields, a total of four high and low pressure system height anomalies (two high, two low) can typically be seen - indicating a wavenumber 2 influence is highly probable. Wavenumber 2 has been implicated in vertical energy transport in several studies (Matsuno, 1970; Kodera, 2002; Matthes et al., 2006). The dynamics of weather systems have secondary circulations which may also contribute to the movement of energy in the central regions of the high and low pressure systems. Different from the previous study (Huang et al., 2012) where the downward energy propagation is weak, the height anomalies make it clear that energy is being transferred vertically in the global- or hemispheric-scale waves associated with the high and low pressure systems which are the lobes of the planetary-scale waves, which clearly shows the role of the stratospheric planetary wave in the tropospheric variation (Shaw and Perlwitz, 2010). Fig. 7 shows the global wind field (streamlines) and 

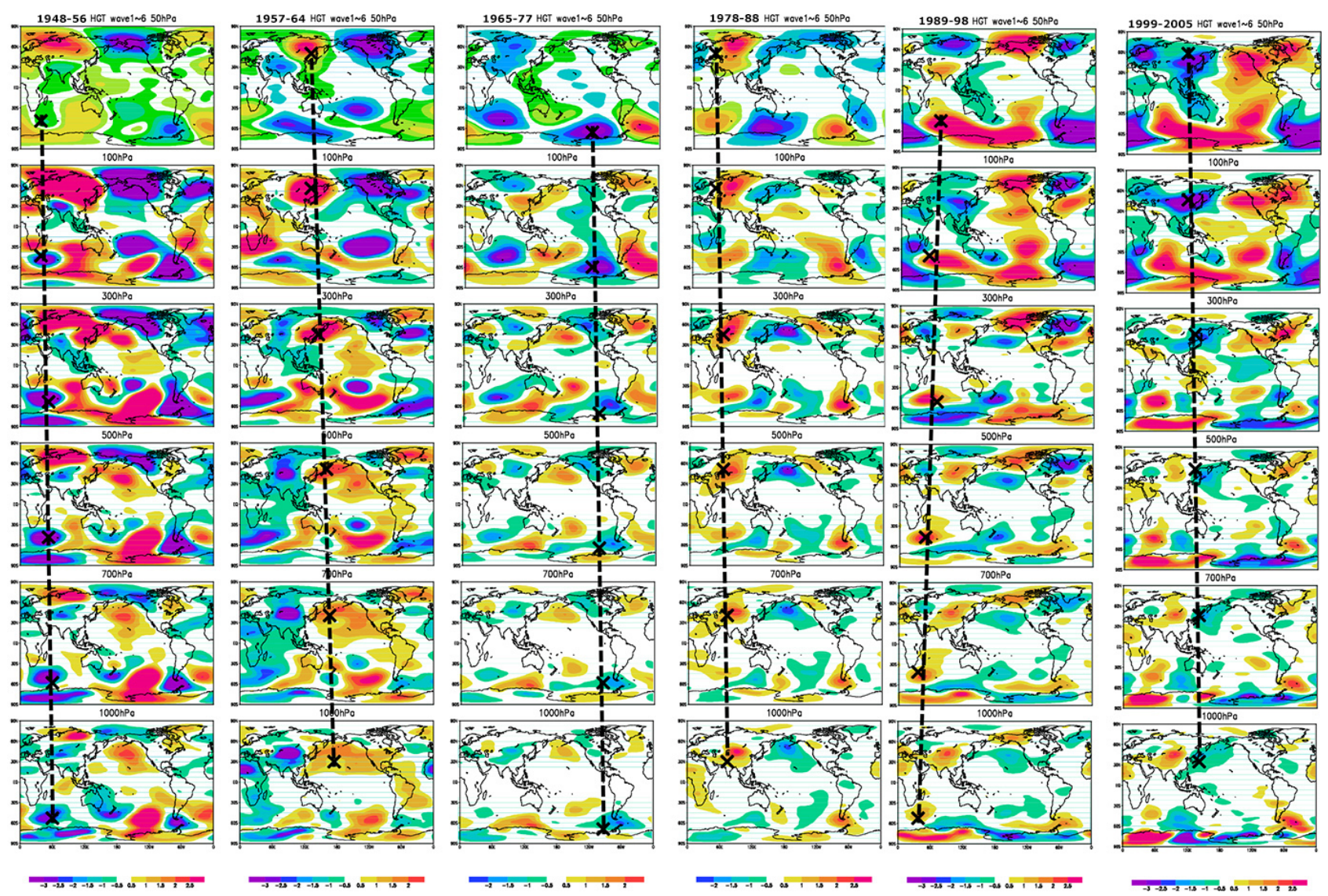

Figure 6. Reconstructed global wave amplitude anomalies from the height fields for planetary wavenumbers $1-6$ with altitude (pressure level). The vertical panels arranged from left to right are the periods in 1948-1956; 1957-1964; 1965-1977; 1978-1988; 1989-1998; and 1999-2005, respectively (negative anomalies: blue-purple shading; positive anomalies: green-yellow-red). The vertical dashed line and " $x$ " give an example during each decadal period representing the connection of the planetary wave active centers between stratosphere, troposphere and Earth's surface $(1000 \mathrm{hPa})$.

height anomalies (shaded areas) near the surface $(1000 \mathrm{hPa})$ for the decadal periods (1948-1956, 1957-1964, 1965-1977, 1978-1988, 1989-1998, 1999-2005). The anomaly positions from the surface $(1000 \mathrm{hPa})$ in Fig. 6 match the colored positions shown in Fig. 7 (note the domain is from $60^{\circ} \mathrm{N}$ to $60^{\circ} \mathrm{S}$ to highlight the wind impact on the oceans compared to Fig. 6 where the domain was from pole to pole). Comparing any two time-sequenced sets of wind and height anomalies emphasizes the differences from the mean surface atmospheric state in the periods before and after each regime shift. Positive height anomalies (yellow-red) are associated with high pressure systems and clockwise wind flows, and negative height anomalies (blue-purple) are associated with low pressure systems and counter-clockwise wind flows in the Northern Hemisphere (note: opposite wind flows occur in the Southern Hemisphere for low and high pressure systems). Since these systems change position and amplitude, it indicates that regional changes are most likely the consequence of these global and hemispheric pattern changes. The key question is whether this can be demonstrated to impact the global marine ecosystems. For this, the analysis will target the three major ocean basins as a demonstration while using the global surface wind stress shown in Fig. 7 as the consistent comparison point for each ocean basin - except in more detail starting with Fig. 8.

\subsection{Regime changes in surface atmospheric-oceanic conditions and corresponding changes in fish landings}

The goal of this section is to demonstrate a connection between the surface atmospheric-oceanic conditions and the marine ecosystems over the Pacific, Atlantic, and Indian oceans as represented by the change in fish landings. The change in fish landings is thought to be caused by the change in large to small-scale surface wind structures which impact marine ecosystems and influences multiple key factors related to fish habitat such as upwelling/downwelling (typically related to feeding) and sea surface temperature advection (related to ecosystem stress and survivability). Each 
NCEP $1000 \mathrm{hPa}$ Wave 1 6 ANOM 1948-56
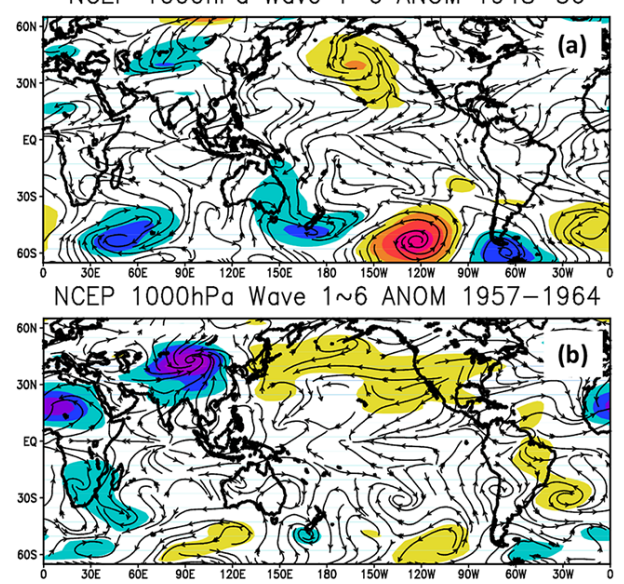

NCEP 1000hPa Wave 1 6 ANOM 1965-77

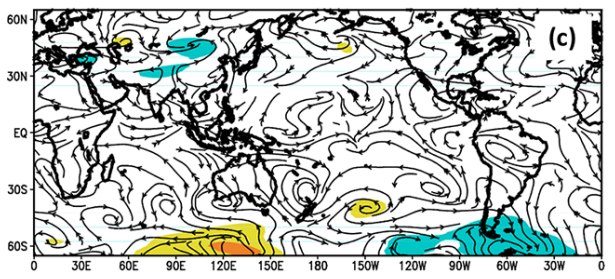

NCEP $1000 \mathrm{hPa}$ Wave $1 \sim 6$ ANOM 1978-88

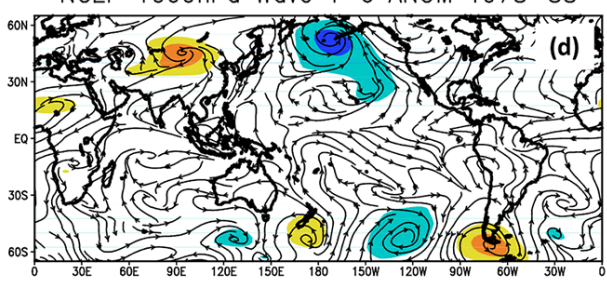

NCEP 1000hPa Wave 1 6 ANOM 1989-98
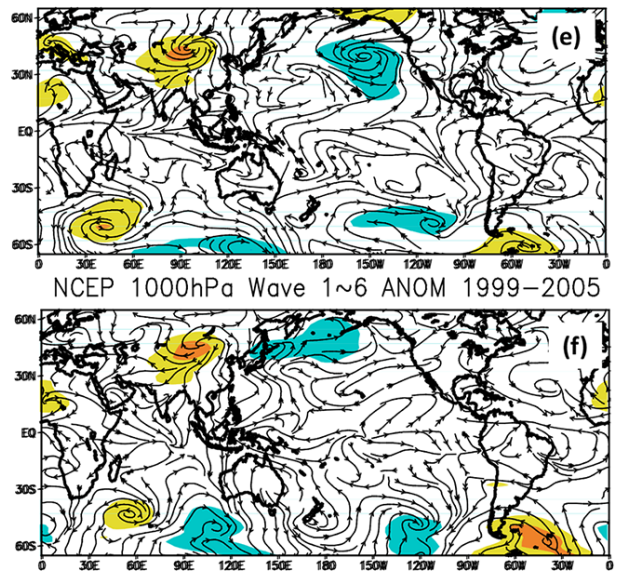

Figure 7. Global regime shift period reconstructed height (shaded) and wind field anomalies (streamlines) at $1000 \mathrm{hPa}$ model level for planetary wavenumbers 1 through 6 . Shaded areas indicate height anomalies exceeding the significance tests at the $90 \%$ confidence level (negative anomaly: blue-purple shading; positive anomaly: green-yellow-red). (a) 1948-1956; (b) 1957-1964; (c) 1965-1977; (d) 19781988 , (e) $1989-1998$, (f) $1999-2005$. Note that the domain shown is from $60^{\circ} \mathrm{S}$ to $60^{\circ} \mathrm{N}$.
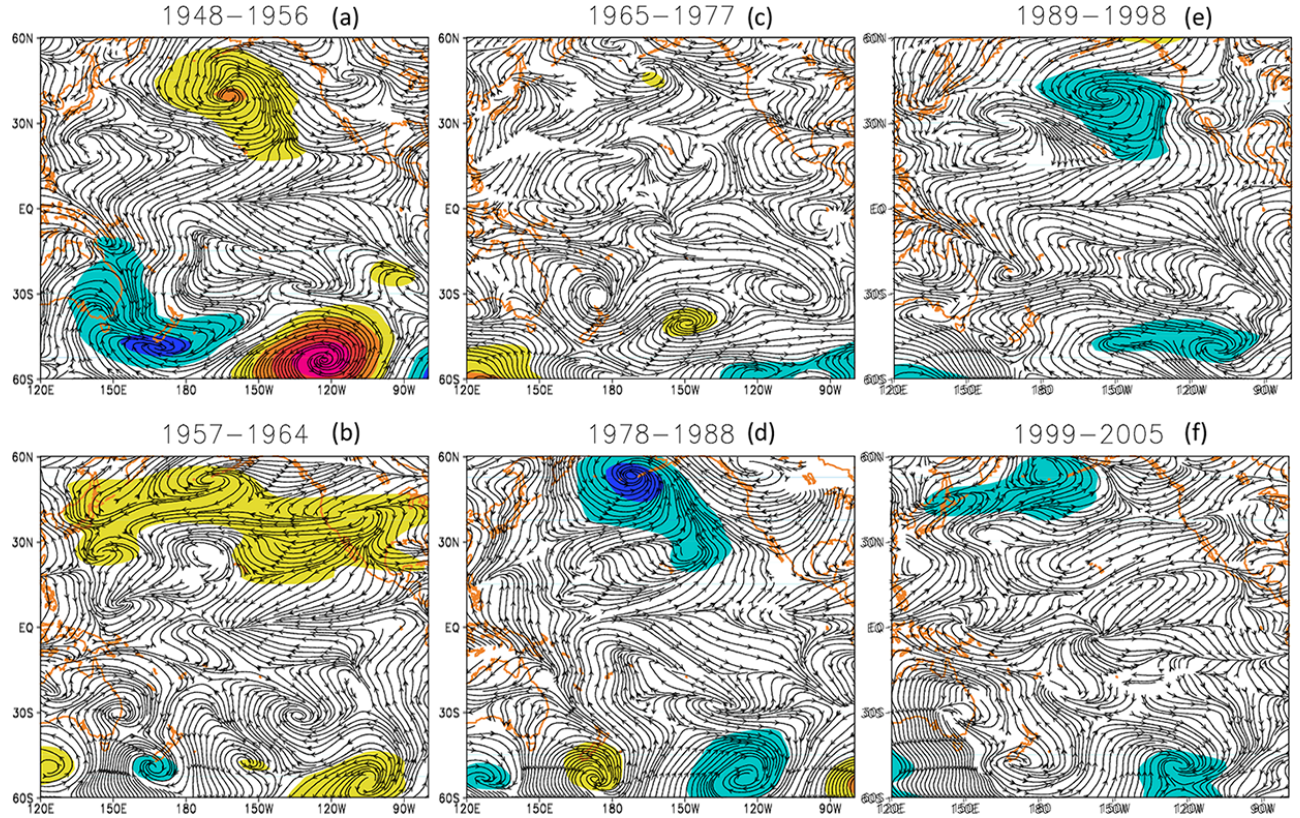

Figure 8. Pacific Ocean reconstructed height (shaded) and wind field anomaly over the Pacific Ocean at $1000 \mathrm{hPa}$ model level for the planetary wavenumbers 1-6. Shaded areas indicate the height anomaly exceeding the significant tests at the $90 \%$ confidence level (negative anomaly: blue-purple shading; positive anomaly: green-yellow-red). (a) 1948-1956; (b) 1957-1964; (c) 1965-1977; (d) 1978-1988, (e) 1989-1998, (f) 1999-2005. Coastline in orange. Note that the domain shown is from $60^{\circ} \mathrm{S}$ to $60^{\circ} \mathrm{N}$ to highlight regions of wind driven forcing over the Pacific Ocean. When the streamlines converge, the water is generally rising or sinking (upwelling and downwelling). 
ocean basin will be shown with its wind streamline analysis and its kinetic energy (KE) wind amplitude analysis compared with its associated normalized fish landings.

\subsection{Pacific Basin}

Figure 7 shows the atmospheric surface wind streamlines and the surface height field anomalies. These surface structures are associated with the stratospheric planetary wave that is dynamically coupled to the ocean surface wind stress through upper level atmospheric forcing. These initial figures are the basis for the ocean surface wind stress discussion. The surface atmospheric height anomalies representative of atmospheric low and high pressure circulations determine the surface wind stress (wind speed and direction) over the Pacific Basin region and the Atlantic and Indian ocean regions as well.

Looking specifically at the Pacific Ocean, Fig. 8 shows the detailed wind stress over the Pacific Basin for each regime shift period. As one scans each regime shift period, there is a noticeable difference in the complexity of the wind stress pattern in the streamline analysis. From the 1948-1956 period to the 1957-1964 and 1965-1977 periods, the wind pattern complexity increases as indicated by more "wind stream swirls" and fewer large sweeping wind flow areas. The complexity of the wind stress pattern has a direct impact on ocean ecosystems.

To demonstrate the increase in complexity that is more rigorous than a simple visual review, a wavenumber analysis of the wind kinetic energy (KE) over each ocean domain shows the change in the wind stress wavenumber spectrum. Figure 9 shows the wind stress through the kinetic energy anomalies characterized by the change in the local wave spectrum over the Pacific Ocean basin (left panels). Figure 9 compares the kinetic energy surface stress wavenumber analysis (left panels) with the normalized fish landings by species (right panels) where decreased (blue bars) and increased (red bars) fish landings can be compared for each sub-region/fish group for each abrupt shift for the Pacific Ocean.

The greater the amplitude of the strongest wavenumber (wavenumber 1), the larger and more "smooth" the wind field structures in each period, even considering the greater structure visible in Fig. 8 (compare with the streamline analysis in Fig. 7). The greater the amplitude of the higher wavenumbers (wavenumbers 2 through 6) in the KE wind anomaly spectrum, the greater the number of small-scale disturbances in the ocean wind stress. The wind flow in the upper left panel of Fig. 8a was dominated by wavenumber 1 (one tall red bar and lower bars for wavenumbers 2 through 6) which shows a few large "swirls" with a number of relatively long connecting flows. Similar large-scale relatively smooth wind flows can be found in the periods of 1950-1956, 1978-1988, and 1989-1998 (Fig. 8a, d, e). The strong local wavenumber 1 influence can be found in the kinetic energy analysis (left panel series) in Fig. 9a, d, e; the black circles rest on top of the red bar with the dominant wavenumber for each regime shift period. Similarly, the periods with the most fish species having positive normalized fish landings are the same periods with strong KE wavenumber 1 influence. In contrast, small-scale vortex flow created with a reduction in wavenumber 1 amplitude and/or an increase of the smaller-scale highwavenumber KE features (wavenumbers 2 through 6) in the Pacific ecosystem can be found in periods 1957-1964, 19651977, and 1999-2005 (Fig. 8b, c, f). These periods are associated with fewer fish species showing positive normalized fish landings (red) and greater numbers of fish species showing negative normalized fish landings (blue).

Based on the FAO sub-regions and groups of fish monitored in the Pacific ecosystem, the fish landings were normalized and presented on the right hand series of graphs in Fig. 9. The number on the axis represents the fish species and region identified per Table A1 in the Appendix. Colored bars are drawn to help highlight the impact of the abrupt shifts on the number of fish species affected in a particular ocean basin. Positive values (red bars) show the fish species with increased catch/landing data and those with blue bars have decreased fish landing/catch data. During relatively largescale stable surface wind field periods (with kinetic energy anomalies in the longest local ocean basin wave, i.e., strong wavenumber 1 influence), the number of fish species with increased normalized landings is greater than during relatively small-scale wind structure periods (with a greater dependence on higher wavenumbers indicating increased smallscale wind structures). In Fig. 9, the wavenumber with the highest amplitude kinetic energy is marked by a black circle on top of the wavenumber bar. The bars with the black circles on top tracks the change in the number of fish species with the greatest fish landing improvements and inversely the number of fish species with reduced landings.

Why should this be true? The ocean consists of multiple ecosystems, albeit fluid ones. When the wind pattern is influenced by large and relatively stable forcing, it creates the opportunity for large-scale features (ecosystems) where the different fish species can thrive with less disruption than during periods where higher wavenumber wind forcing is dominant. While there are a number of factors that can affect the viability of an ecosystem, the impacts of SST change, spawning temperature impacts, growth of algae for feeding, and upwelling/downwelling are likely to be among the strongest, and all can be impacted by the wind pattern. This conclusion presumes that the fish landing data accurately reflect changes in fish habitat and does not reflect changes in policy for fish catch or other artificial constraints that would change the conclusions of the analysis (Daw et al., 2009).

When the wind stress pattern is dominated by smallerscale features (higher KE wavenumbers), it disrupts the ocean ecosystems, creating more discontinuous and generally less favorable conditions across the ocean basin. This adds stress to each fish species seeking an environment in which it can thrive and is thought to affect environmen- 

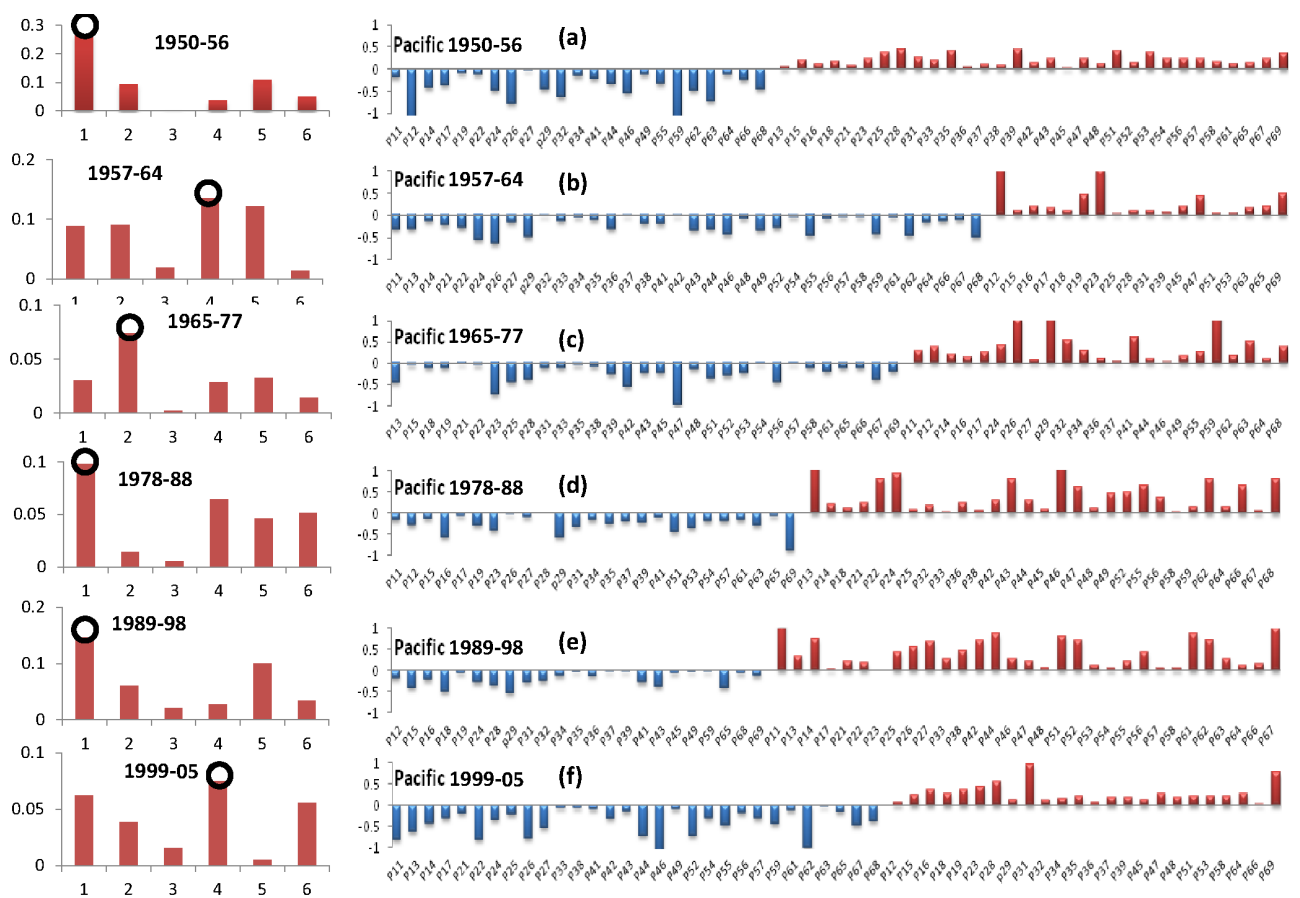

Figure 9. Pacific Ocean. Left panel indicates the wave kinetic energy anomaly $1 / 2\left(u^{2}(n)+v^{2}(n)\right)$ with wavenumber ( $x$ axis). Right panel indicates the average normalized fish landings for the Pacific Ocean for each species in the periods coincident with abrupt climate regime shifts. (a) 1950-1956, (b) 1957-1964, (c) 1965-1977, (d) 1978-1988, (e) 1989-1998, and (f) 1999-2005. The $x$ axis code number indicates both the geographical ocean sub-region (shown in Fig. 1) and the FAO fish species category. The codes are summarized in Table A1 of the Appendix.

tal stress and survivability. As a consequence, when the ocean wind stress is dominated by higher wavenumber kinetic energy anomalies, the general fish populations do less well over the entire ocean basin which is broken into multiple, distributed, and more stressful living conditions. Which fish do better and worse is highly dependent on the needs of each fish species and is a convolution of the changes induced by the wind stress, the geographic ocean locations most affected, and the resulting environmental impacts (upwelling/downwelling, SST change, algal growth change, etc.).

In general, it appears that the atmospheric circulation starting at stratospheric levels is vertically communicated to the Earth's surface and impacts ocean circulation. In this analysis, the mid- to high-latitude atmospheric wave and wind patterns are demonstrated as drivers of complex ocean basin wind stress change that results in the fish landing patterns shown in this research. The global atmospheric wave pattern changes across the multiple regime shift boundaries appear to be responsible for the significant changes in the surface ocean corresponding to more and less complex surface wind stress patterns, with the resulting change in the number of fish species doing better or worse. Whether this is due to actual fish populations changes, the migration of fish to regions more conducive for survival (less stressful conditions), or other factors is not completely clear. However, the driving physical factors analyzed in this research are among those known to create changes in fish species abundance. More detailed analysis of individual physical changes and their impacts on specific fish species is an area for future research.

The net result of the Pacific Ocean analysis is that ocean wind stress forcing with large wind stress features (reflecting KE wavenumber 1) produces greater numbers of fish species with improved fish catch/landings. Conversely, the regime shift periods with higher wavenumber wind stress impacts (more smaller-scale wind stress features) leads to diminished numbers of fish species doing well (or more fish species with lower catch and landing numbers). The next step is to determine whether this holds true for the Atlantic and Indian oceans.

\subsection{Atlantic Basin}

Similar to the smooth (wavenumber 1 dominant) and complex (higher wavenumber dominant) wind stress patterns in the Pacific ocean, the wind stress pattern in the Atlantic Ocean (Fig. 10) shows a close relationship with the normalized fish species landings (Fig. 11), even though the Atlantic Ocean basin has a number of characteristics dissimilar to the Pacific Ocean. The Atlantic Ocean is significantly narrower than the Pacific Ocean, and the wind stress has fewer large fetch patterns like those seen in the Pacific Ocean. However, 

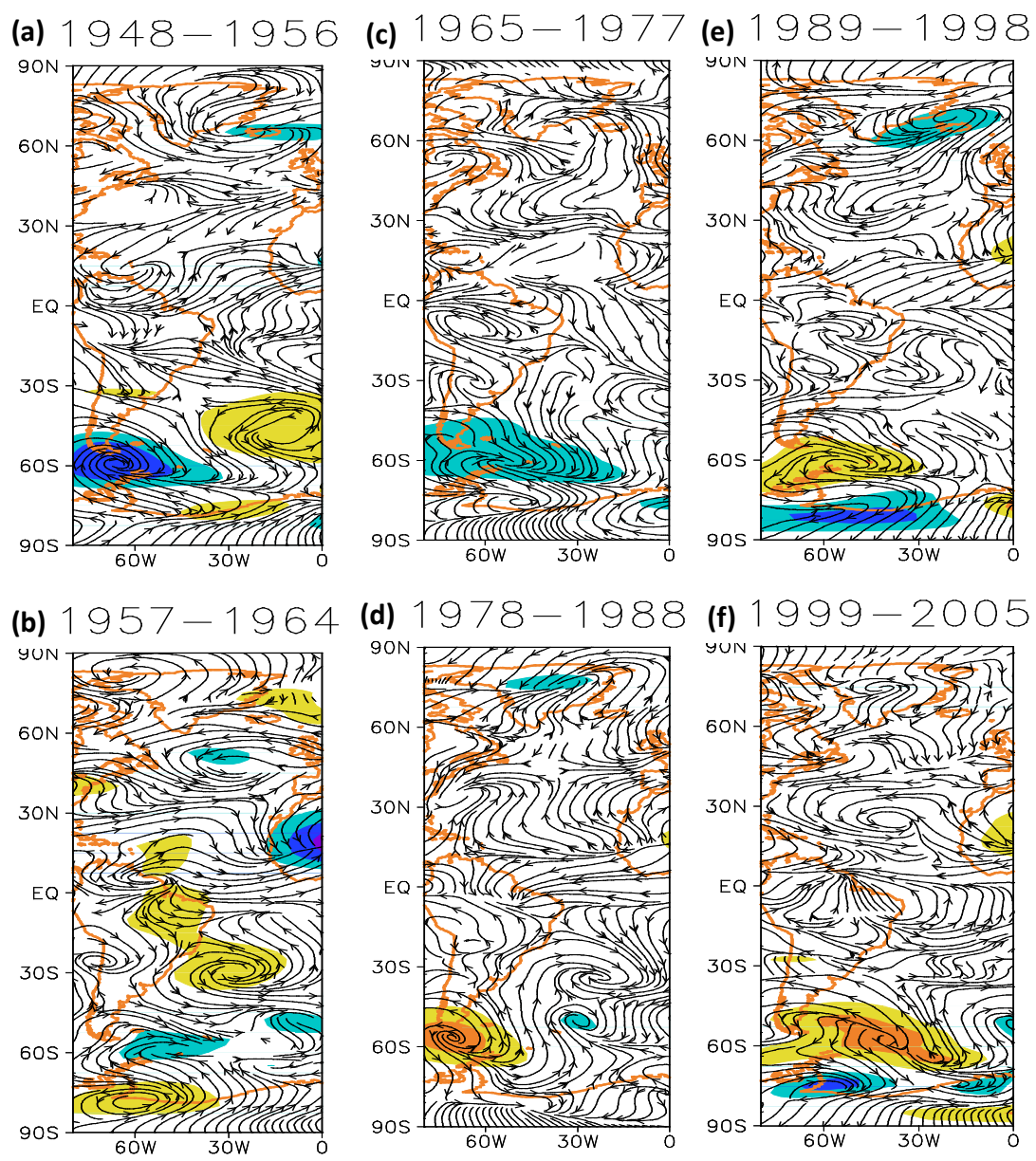

Figure 10. Atlantic Ocean reconstructed height (shaded) and wind field anomaly over the Atlantic Ocean at $1000 \mathrm{hPa}$ model level for the planetary wavenumbers 1-6. Shaded areas indicate the height anomaly exceeding the significant tests at the $90 \%$ confidence level (negative anomaly: blue-purple shading; positive anomaly: green-yellow-red). (a) 1948-1956; (b) 1957-1964; (c) 1965-1977; (d) 19781988, (e) 1989-1998, (f) 1999-2005. Coastline in orange.

when the large-scale wavenumber 1 wind stress anomaly pattern (left panels in Fig. 11) dominates in a regime period, the fish landings are positively impacted. The wavenumber 1 dominant wind stress pattern in the Atlantic Ocean occurs in the periods of 1965-1977 and 1978-1988 (left panels in Fig. 11c, d), corresponding with more positive normalized fish landings in the same periods (right panels in Fig. 11c, d). The opposite patterns can be found in the other four periods (Fig. 11a, b, e, f) when higher KE wavenumber impacts (greater number of relatively small-scale ocean surface wind stress features) are present.

Fish species change in the Atlantic Ocean is impacted by the changes in relatively smooth (large-scale) and complex (small-scale) wind stress change. When wavenumber 1 wind stress features dominate this region, more fish species do well. Conversely, when higher wavenumber wind features are present, fewer numbers of fish species do well (or conversely more fish species have lower fish catch).

\subsection{Indian Basin}

The Indian Ocean wind pattern is largely tropical, and the ocean is bounded on the north and west by continents. This creates circumstances different from the mid-latitude wind stress patterns in the Pacific and Atlantic oceans. However, the wind flow patterns over the Indian Ocean provide the same net tendency reinforcing the conclusion that the wind stress impacts fish. Consequently, the wind stress pattern in the Indian Ocean (Fig. 12) shows a similar relationship with the fish landings as the Pacific and Atlantic oceans, which were related to wavenumber 1 wind stress patterns (Fig. 13). However, the Indian Ocean may be more dependent on the specific high-wavenumber wind structures than the other two ocean basins. It appears that the high-wavenumber wind stress patterns coupled with a reduced interchange with the southern polar region may create larger impacts on the number of fish species with positive fish landings. 


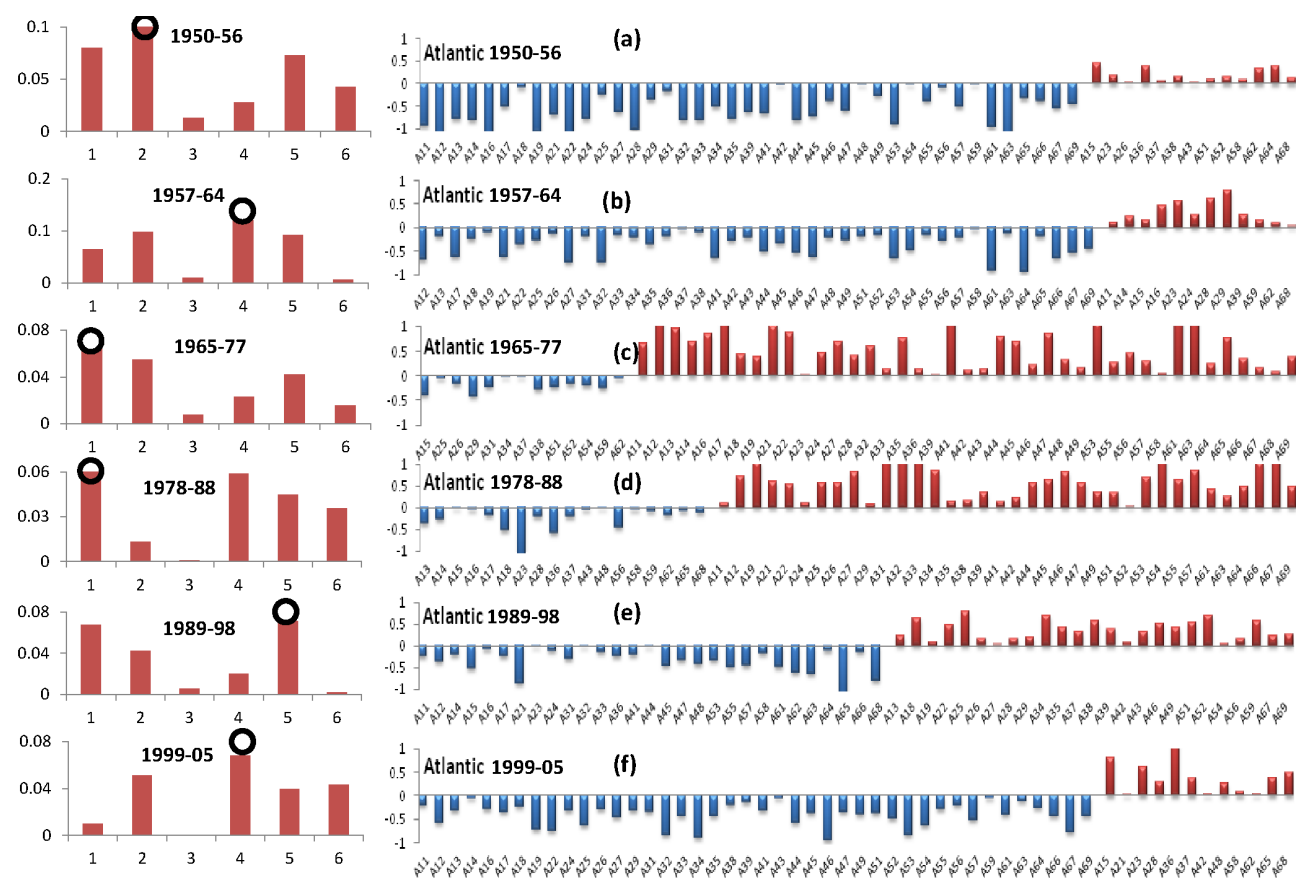

Figure 11. Atlantic Ocean. Left panel indicates the wave kinetic energy anomaly $1 / 2\left(u^{2}(n)+v^{2}(n)\right)$ with wavenumber $(x$ axis). Right panel indicates the average normalized fish landings for the Pacific Ocean for each species in the periods coincident with abrupt climate regime shifts. (a) 1950-1956, (b) 1957-1964, (c) 1965-1977, (d) 1978-1988, (e) 1989-1998, and (f) 1999-2005. The $x$ axis code number indicates both geographical ocean sub-region (shown in Fig. 1) and the FAO fish species category; the codes are summarized in Table A1 of the Appendix.
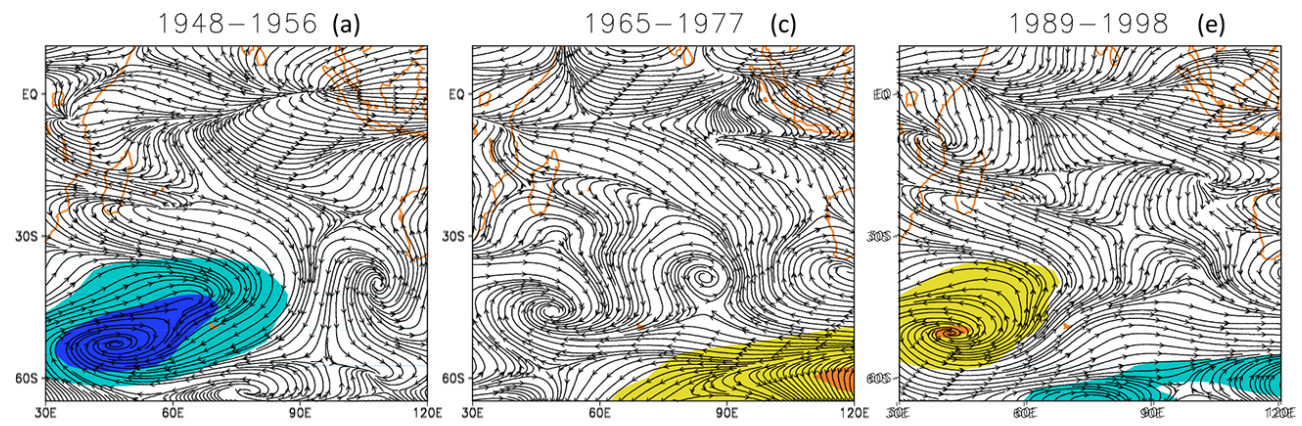

1957-1964 (b)

$1978-1988$ (d)

$1999-2005$ (f)
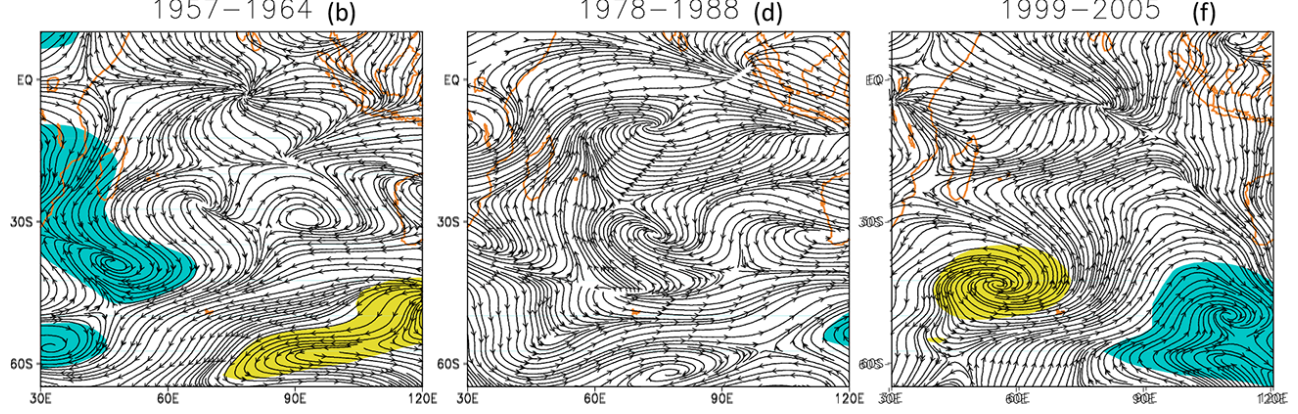

Figure 12. Indian Ocean reconstructed height (shaded) and wind field anomaly over the Indian Ocean at $1000 \mathrm{hPa}$ model level for the planetary wavenumbers 1-6. Shaded areas indicate the height anomaly exceeding the significant tests at the $90 \%$ confidence level (negative anomaly: blue-purple shading; positive anomaly: green-yellow-red). (a) 1948-1956; (b) 1957-1964; (c) 1965-1977; (d) 1978-1988, (e) 1989-1998, (f) 1999-2005. Coastline in orange. Note the latitude range for the Indian Ocean. 


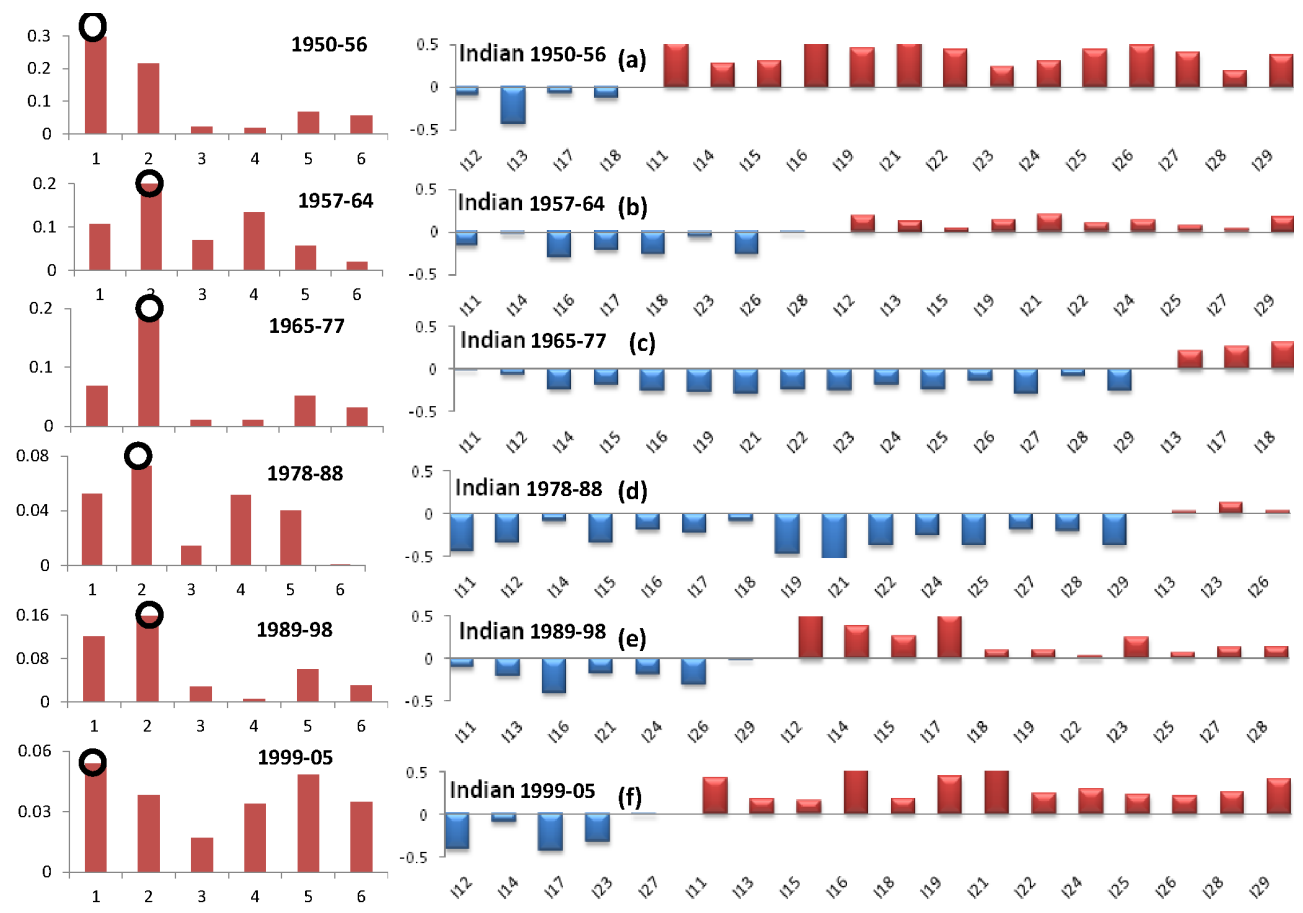

Figure 13. Indian Ocean. Left panel indicates the wave kinetic energy anomaly $1 / 2\left(u^{2}(n)+v^{2}(n)\right)$ with wavenumber ( $x$ axis). Right panel indicates the average normalized fish landings for the Pacific Ocean for each species in the periods coincident with abrupt climate regime shifts. (a) 1950-1956, (b) 1957-1964, (c) 1965-1977, (d) 1978-1988, (e) 1989-1998, and (f) 1999-2005. The $x$ axis code number indicates both geographical ocean sub-region (shown in Fig. 1) and the FAO fish species category. The codes are summarized in Table A1 of the Appendix.

In the periods where KE wavenumber 2 and higher wavenumber wind stress patterns were dominant, more fish species showed fewer positive fish landings in the regime periods from 1957-1964 through 1989-1998 (panels in Fig. 13b, c, d, e). In looking at the wavenumber 2 dominant periods, the greatest impact occurred with wavenumber 1 at its lowest magnitude (1978-1988, note the change in scale for the figures in the left series of panels) and the northsouth interchange with the southern polar region reduced (Fig. 12d). For the other wavenumber 2 wind stress dominant regime shifts, there is increased amplitude in wavenumbers 3 through 6. During the four wavenumber 2 and higher dominant periods, the impact is addressed by both the reduction in wavenumber 1 features and generally increased wavenumber 3 through 6 activity. The combination of wavenumber influence and cut-off polar flow reduces the number of fish species doing well in the Indian Ocean, with the 1957-1964, 19651977, 1978-1988 and 1989-1998 periods having the fewest fish species doing well as indicated by the normalized fish catch. This is contrasted with the periods of 1950-1956 and 1999-2005, where the wavenumber 1 dominant wind stress anomaly leads to substantially improved numbers of fish species doing well based on higher normalized fish landings. In these periods, large-scale wind circulation patterns connect with the mid-latitude and polar zones and are thought to create conditions more conducive to greater numbers of fish species thriving. Also, sustaining higher wavenumber wind stress conditions appear to result in declining periods of positive fish landing anomalies. The periods with highwavenumber activity in the Indian Ocean tend to cut off the interchange of ocean flow with the southern polar region and appears to worsen the impact of the high-wavenumber wind stress conditions. Recovery of the number of normalized fish landings in the later three regime shift periods appears to also be a result of both the ocean wind stress and the increasing interchange with the southern polar ocean region.

\section{Discussion}

Surface wind stress can create many changes in the ocean including zones of upwelling and downwelling which can impact feeding, the ocean temperatures, and the availability of food. It can also affect the advection of warm or cold water, spawning temperatures, the creation of ocean fronts, etc. Many of these factors can affect an ocean ecosystem, so the picture is not as simple as the analysis portrays since it does not identify individual factors affecting specific fish populations consistently or how the ecosystem improved to cause the improved fish landings. However, this analysis does satisfy Chavez's basic premise (2003) that the forcing mechanisms need to be global (hemispheric), simple, direct, and 
coupled with biological changes identified in the fish catch. In this analysis, the global atmospheric pattern is the significant driver of the ocean surface through wind stress. The atmospheric winds and circulation patterns are the variables linked in this analysis to the normalized fish landings. The linkage is logical and explains how the synchrony of fish species changes in all the world's ocean basins could occur based on changes in the global atmospheric wave pattern that influences ocean systems.

The authors suggest that the global atmospheric wind stress forcing from the Earth's largest atmospheric waves is the driving mechanism. When the wind stress is more complex and more disruptive in the ocean basins, the number of fish species doing well decrease or conversely, the number of fish species doing poorly increase. This suggests that when an ocean basin has greater fine-scale wind structure, it disrupts the ocean ecosystems and stresses the various fish species causing them to adapt, migrate, or possibly suffer higher mortality due to stressful ocean habitat conditions. In terms of upwelling and downwelling alone, a case can be made that during low KE wavenumber dominant conditions, relatively large consistent areas with potential for easily increasing the ability of the fish to feed appear to develop. When high KE wavenumber winds develop, there are many smaller upwelling areas that could increase the stress in finding suitable ocean-assisted feeding areas, thereby reducing the size of the fish catch. Habitat stress will affect the ability of the fish to thrive. In response to the atmospheric wind stress forcing on the ocean surface, it is likely that multiple conditions change in an ocean ecosystem that contribute to the overall impacts on a complex food chain and other factors which may impact survival and overall stress. Spawning temperatures affect some species (Takasuka et al., 2008), while the wind impacts on upwelling and downwelling can affect food availability similar to the well-known El NiñoSouthern Oscillation (ENSO) impacts off South America. Analogously, the ENSO changes in surface wind direction, SST temperature, and upwelling/downwelling impacts many fish species off South America and significantly reduces fish catch in the region. Fish species may be directly or indirectly impacted through the wind stress on ocean ecosystems through changes in the food chain or the ability to reproduce, or they may be forced to migrate to more suitable ocean conditions. The fish catch changes according to how turbulent or disruptive the KE wind forcing flow is. There are likely multiple factors affecting fish catch. However, the global wind forcing derived from the decadal global (hemispheric) weather pattern plays a dominant role in sub-regional/fish species groups that result in increased or decreased fish catch. The change in the wind stress conditions impact about 15$25 \%$ of the FAO sub-region/fish species groups across the identified decadal regime shifts.

In fact, the impact on fish landings is even more consistent across the ocean basins when the number of fish species impacted is considered. In Table A3, the regime shifts which had five or more fish species change from one regime shift period to the next are shown when a similar change occurs in the other ocean basins. A change of five or greater fish species represent approximately $9 \%$ or greater change in the Pacific and Atlantic and an approximately $26 \%$ or greater change in the Indian Ocean. Using the five fish species change as a benchmark, one can compare the regime shift impact on the fisheries in the three ocean basins using the analyses from Figs. 9, 11, and 13. When this comparison is made, the regime shifts with the largest impacts on the fish clearly stand out. The three most impactful regime shifts, from a fishery change perspective, are 1964-1965, 1988-1989, and 1998-1999. When this analysis is performed, it is clear in Table A3 that the same regime shifts strongly affected the fish species in all three ocean basins. This supports the Chavez et al. (2003) hypothesis about a global mechanism affecting all the world's ocean basins in synchrony. The key difference in Table A3 is that the 1998-1999 shift was not as impactful in the Indian Ocean as the other ocean basins likely due to reasons discussed previously. Why should relatively high numbers of fish species changes occur with these shifts? Reviewing Fig. 5, if one looks at the positions of the large high and low height centers in the Northern Hemisphere, their central regions tend to be over central Asia and the North American continent. The changes across 1964-1965, 1988-1989, and 1998-1999 shows the strongest height centers situated more over the ocean, maximizing the impact of the wind shifts and the corresponding wind stress. Since this paper analyzed the impact of the global atmospheric planetary wave pattern on the ocean wind stress and the corresponding fish species changes, it is logical that the greatest impacts would occur with the largest surface area of these systems in maximum contact with an ocean basin (typically the Pacific and North Atlantic). Further research should address the positions of the weather systems and the impact of the wind stress regionally to tie past research in this area with the current global evidence.

\section{Conclusions}

Based on the analysis of the global wave pattern forcing, the consequential changes in ocean surface wind stress and the subsequent impacts on fish catch were investigated. The global wave pattern structure (KE wavenumber influence) and its amplitude are likely the key forcing mechanisms that cause near-synchronous impacts on the world's oceans and subsequently impact ocean ecosystems resulting in changes in fish catch.

As an extension to previous research, the atmospheric planetary wave processes were investigated as a likely global forcing in the six regime shift periods (1948-1956, 19571964, 1965-1977, 1978-1988, 1989-1998, and 1999-2005) in both the atmospheric and fish catch data in the most recent 59-year period (1950-2008). The multiple regime shifts 
across 1956-1957, 1964-1965, 1977-1978, 1988-1989, and 1998-1999 appear to support the wave amplitude and wind stress coupling mechanism. The analysis of five regime shifts and six periods has clearly identified a mechanism where stratospheric planetary wave amplitudes may cause changes in surface atmospheric wind conditions. The decadal wave amplitude changes modify the winds through large contiguous systems which transfer energy between the stratosphere, troposphere, and the ocean surface via height field anomalies (indicative of vertical atmospheric processes) which extend throughout the atmosphere.

The surface atmospheric conditions show a significant consistent mechanism responsible for the fishery regime shifts in the catch/landing numbers of the three major ocean basins. In all three of the Earth's major ocean basins (Pacific, Atlantic, and Indian), the large-scale atmospheric circulation's kinetic energy wind stress anomaly is best associated with the local wavenumber 1 surface wind stress which results in increases in fish landings. Higher KE wavenumber wind stress is associated with decreases in fish landings. It is thought that the larger-scale ocean features lead to ocean ecosystem conditions conducive to most fish species thriving through reduced habitat stress or improved habitat conditions. Conversely, when the wind stress anomalies have many smaller-scale wind features (increased habitat stress), it is disruptive to the ocean ecosystems placing stress on the fish species to find more acceptable ocean conditions. The stress of adaptation or migration and general survivability are consequences of the many ocean ecosystem changes where smaller-scale wind stresses can impact the ability of an ocean fish species to thrive as indicated by decreased fish landings.
The decadal regime shift linkage between global marine fish landings and atmospheric planetary wave forcing was demonstrated. The link between atmospheric waves that propagate to the Earth's surface and the ocean wind stress was shown. Similarly, the linkage between the ocean surface wind stress and fish landings was portrayed in graphical form. The decadal global connection between the atmospheric wind forcing and changes in fish catch in the world's three major ocean basins verifies the Chavez hypothesis that the synchronous changes in fish populations are due to a consistent mechanism that is simple, direct, and operates similarly in all the world's oceans. In addition, the analysis showed the sub-region/fish species changes associated with the decadal regime shifts are of the order of 15 to $25 \%$. This is a significant finding that helps quantify the impacts associated with decadal climate and regime shift change. 
Appendix A

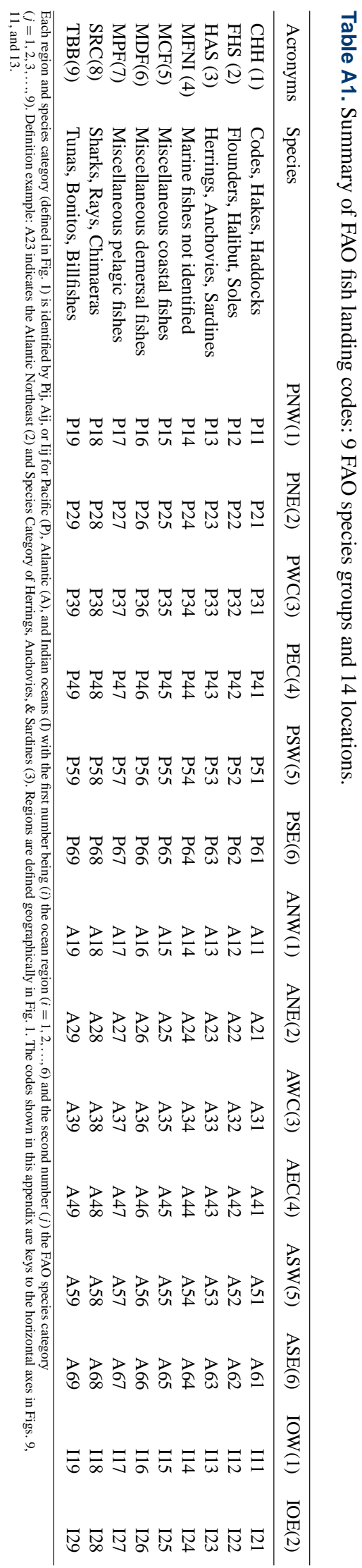


Table A2a. Listed years of fish landing regime shift occurrence by region and species consolidated by decade from 1950 to 2008 . (a) Indicates the fish species over the Atlantic and Pacific oceans.

\begin{tabular}{|c|c|c|c|c|c|c|c|c|c|c|c|}
\hline Decade & $\begin{array}{r}1951- \\
1960\end{array}$ & $\begin{array}{r}1961- \\
1970\end{array}$ & $\begin{array}{r}1971- \\
1980\end{array}$ & $\begin{array}{r}1981- \\
1990\end{array}$ & $\begin{array}{r}1991- \\
2000\end{array}$ & Decade & $\begin{array}{r}1951- \\
1960\end{array}$ & $\begin{array}{r}1961- \\
1970\end{array}$ & $\begin{array}{r}1971- \\
1980\end{array}$ & $\begin{array}{r}1981- \\
1990\end{array}$ & $\begin{array}{r}1991- \\
2000\end{array}$ \\
\hline PNW-CHH & 56 & & $72 \& 78$ & 88 & 99 & ANW-CHH & 60 & 70 & 76 & 81 & 99 \\
\hline PNW-FHS & 59 & & 77 & 88 & 98 & ANW-FHS & & 65 & 74 & 88 & 94 \\
\hline PNW-HAS & 59 & & 76 & & 92 & ANW-HAS & & 68 & 74 & 87 & \\
\hline PNW-MFNI & 55 & 65 & 74 & 88 & & ANW-MFNI & 55 & & 76 & & \\
\hline PNW-MCF & & 65 & & & & ANW-MCF & & 61 & 76 & 89 & 96 \\
\hline PNW-MDF & 55 & & 76 & 86 & 94 & ANW-MDF & 58 & & 76 & 86 & 94 \\
\hline PNW-MPF & 58 & & & & 98 & ANW-MPF & 57 & & $73 \& 78$ & 85 & 92 \\
\hline PNW-SRC & & 64 & 76 & 88 & 99 & ANW-SRC & 55 & & 77 & 85 & \\
\hline PNW-TBB & 57 & 64 & & & & ANW-TBB & & 63 & & & 94 \\
\hline PWC-CHH & 60 & 68 & & 86 & 91 & ANE-CHH & & 68 & & 89 & \\
\hline PWC-FHS & & 63 & 75 & 84 & 99 & ANE-FHS & & 68 & 74 & 85 & 92 \\
\hline PWC-HAS & & 67 & 73 & 84 & 99 & ANE-HAS & & 69 & 77 & 85 & 94 \\
\hline PWC-MFNI & 55 & & 74 & 83 & & ANE-MFNI & 56 & 69 & 77 & & \\
\hline PWC-MCF & & 62 & & 87 & 97 & ANE-MCF & & & 77 & & \\
\hline PWC-MDF & & 66 & 77 & 87 & 2000 & ANE-MDF & & 66 & & 89 & \\
\hline PWC-MPF & & & & & & ANE-MPF & & 67 & 77 & 87 & \\
\hline PWC-SRC & 58 & 66 & & 89 & 97 & ANE-SRC & 56 & & & 84 & 97 \\
\hline PWC-TBB & & 66 & 79 & & 94 & ANE-TBB & 57 & 63 & & 86 & 2000 \\
\hline PSW-CHH & & & & 81 & 91 & AWC-CHH & & 61 & & & \\
\hline PSW-FHS & & 61 & 76 & 90 & & AWC-FHS & & 64 & 74 & 89 & \\
\hline PSW-HAS & 57 & 70 & & 89 & & AWC-HAS & 59 & & 78 & 88 & \\
\hline PSW-MFNI & & 63 & 74 & 86 & & AWC-MFNI & 57 & & & 81 & 95 \\
\hline PSW-MCF & 58 & 63 & 79 & 86 & 93 & AWC-MCF & 55 & 65 & & 90 & 98 \\
\hline PSW-MDF & 60 & 67 & 77 & 89 & & AWC-MDF & 58 & 63 & 72 & 89 & 98 \\
\hline PSW-MPF & 55 & 65 & 79 & & 2000 & AWC-MPF & & & 78 & & \\
\hline PSW-SRC & 58 & 65 & & 89 & 97 & AWC-SRC & 57 & 70 & & 81 & 99 \\
\hline PSW-TBB & 60 & & & 88 & & AWC-TBB & 57 & 67 & & 87 & \\
\hline PNE-CHH & 55 & 61 & & & & AEC-CHH & & 65 & 78 & & \\
\hline PNE-FHS & & 64 & $71 \& 78$ & & & AEC-FHS & 57 & & 71 & 86 & 91 \\
\hline PNE-HAS & 60 & & 75 & 90 & & AEC-HAS & 60 & 70 & 79 & 87 & 92 \\
\hline PNE-MFNI & & 67 & 74 & & 99 & AEC-MFNI & 55 & 64 & & & \\
\hline PNE-MCF & & 70 & & 90 & & AEC-MCF & & 63 & $72 \& 77$ & 88 & \\
\hline PNE-MDF & 57 & 63 & 74 & & 99 & AEC-MDF & 57 & 68 & & & 99 \\
\hline PNE-MPF & & 65 & 77 & & 92 & AEC-MPF & 55 & 69 & & 90 & \\
\hline PNE-SRC & 59 & & 78 & & & AEC-SRC & 57 & & 71 & 81 & 97 \\
\hline PNE-TBB & 55 & 70 & & 85 & & AEC-TBB & & 68 & 74 & 90 & \\
\hline PEC-CHH & & 69 & & 87 & & ASW-CHH & 56 & & 77 & & 99 \\
\hline PEC-FHS & 55 & & 77 & & 98 & ASW-FHS & & 63 & & 85 & 99 \\
\hline PEC-HAS & & 61 & 71 & & 92 & ASW-HAS & 55 & 62 & 71 & 88 & 99 \\
\hline PEC-MFNI & 56 & & & & & ASW-MFNI & 56 & 67 & & 90 & \\
\hline PEC-MCF & 60 & 70 & & & & ASW-MCF & 56 & 68 & 76 & 88 & \\
\hline PEC-MDF & 56 & 64 & 80 & & & ASW-MDF & 59 & & 80 & 86 & \\
\hline PEC-MPF & 56 & 62 & & & & ASW-MPF & & 63 & & 87 & \\
\hline PEC-SRC & 55 & 68 & 80 & & & ASW-SRC & 59 & 64 & & & 97 \\
\hline PEC-TBB & & 64 & & 83 & & ASW-TBB & & 65 & 80 & & \\
\hline PSE-CHH & 58 & & & 87 & & ASE-CHH & & 66 & 79 & 90 & \\
\hline PSE-FHS & & 66 & & & 96 & ASE-FHS & & & 75 & 89 & \\
\hline PSE-HAS & & 61 & 72 & 85 & & ASE-HAS & 56 & & 80 & & 2000 \\
\hline PSE-MFNI & & & & & 92 & ASE-MFNI & & 66 & & & \\
\hline PSE-MCF & 57 & 64 & & & & ASE-MCF & & 64 & 80 & 89 & 98 \\
\hline PSE-MDF & 55 & & & 86 & & ASE-MDF & 59 & & & 90 & \\
\hline PSE-MPF & 60 & & 77 & 88 & 98 & ASE-MPF & & 64 & 77 & 84 & 2000 \\
\hline PSE-SRC & & 66 & & & & ASE-SRC & & 66 & & 84 & 99 \\
\hline PSE-TBB & & 64 & 73 & 88 & & ASE-TBB & & 62 & & & \\
\hline
\end{tabular}


Table A2b. (b) Indicates the fish species over the Indian Ocean.

\begin{tabular}{lrrrrr}
\hline Decade & $\begin{array}{r}1951- \\
1960\end{array}$ & $\begin{array}{r}1961- \\
1970\end{array}$ & $\begin{array}{r}1971- \\
1980\end{array}$ & $\begin{array}{r}1981- \\
1990\end{array}$ & $\begin{array}{r}1991- \\
2000\end{array}$ \\
\hline IOW-CHH & & & 75 & & 2000 \\
IOW-FHS & & & & 90 & \\
IOW-HAS & & 64 & & & 2000 \\
IOW-MFNI & & 64 & 78 & 84 & 97 \\
IOW-MCF & 58 & 67 & 80 & & 91 \\
IOW-MDF & 56 & 61 & 74 & & 97 \\
IOW-MPF & & 70 & 80 & 89 & 2000 \\
IOW-SRC & & 66 & & 83 & 91 \\
IOW-TBB & 57 & & 75 & 85 & 92 \\
IOE-CHH & 59 & & 78 & 88 & 98 \\
IOE-FHS & 55 & 69 & 80 & 81 & 95 \\
IOE-HAS & 57 & 68 & 77 & 86 & $93 \& 99$ \\
IOE-MFNI & & 64 & & 89 & 2000 \\
IOE-MCF & 58 & & 79 & 89 & 96 \\
IOE-MDF & 60 & & & 86 & \\
IOE-MPF & 57 & 70 & & 83 & 2000 \\
IOE-SRC & 55 & & & & 93 \\
IOE-TBB & 58 & 70 & & & 96 \\
\hline
\end{tabular}

The listed number is the year of the fish landing regime shift occurrence during each decade based on the 11-year running Student $t$ test for the normalized time series of one fish species from 1950 to 2008 at the $90 \%$ significance confidence level. For example, the fish species group $\mathrm{CHH}$ over the Northwest Pacific (PNW-CHH) in Fig. 3b shows that the $t$ test value exceeds the statistical significance test at the $95 \%$ confidence level in the years 1956, 1972, 1978, 1988, and 1999 , which corresponds with $56,72 \& 78,88$, and 99 in the table at the row for PNW-CHH.

Table A3. Consistent regime shift impacts on fish species across the ocean basins (with greater than five fish species impacted across the regime shift boundary identified).

\begin{tabular}{lrc}
\hline Pacific Ocean & Atlantic Ocean & Indian Ocean \\
\hline $1956-1957$ & & \\
$1964-1965$ & $1964-1965$ & $1964-1965$ \\
$1977-1978$ & $1977-1978$ & \\
& $1988-1989$ & $1988-1989$ \\
$1998-1999$ & $1998-1999$ & \\
\hline
\end{tabular}


Acknowledgements. The NCEP/NCAR monthly reanalysis data were obtained from NOAA/CDC web site. The authors would like to thank these agencies for providing the data. Special thanks to FAO for the fisheries data sets that were provided.

This work was supported by the National Oceanic and Atmospheric Administration (NOAA), National Environmental Satellite, Data, and Information Service (NESDIS), Center for Satellite Applications and Research (STAR).

The views, opinions, and findings contained in this publication are those of the authors and should not be considered an official NOAA or US Government position, policy, or decision.

Edited by: N. Zeng

\section{References}

Beamish, R. J., Benson, A. J., Sweeting, R. M., and Neville, C. M.: Regimes and the history of the major fisheries off Canada's west coast, Prog. Oceanogr., 60, 355-385, 2004.

Chavez, F. P., Ryan, J., Lluch-Cota, S. E., and Niquen, M. C.: From anchovies to sardines and back: multidecadal change in the Pacific Ocean, Science, 299, 217-221, 2003.

Chelton, D. B., Esbensen, S. K., Schlax, M. G., Thum, N., Freilich, M. H., Wentz, F. J., Gentemann, C. L., McPhaden, M. J., and Schopf, P. S.: Observations of coupling+ between surface wind stress and sea surface temperature in the eastern tropical Pacific, J. Climate, 14, 1479-1497, 2001.

Daw, T., Adger, W. N., Brown, K., and Badjeck, M. C.: Climate change and capture fisheries: potential impacts, adaptation and mitigation, in: Climate change implications for fisheries and aquaculture: overview of current scientific knowledge, edited by: Cochrane, K., De Young, C., Soto, D., and Bahri, T., FAO Fisheries and Aquaculture Technical Paper, No. 530, Rome, FAO, 107-150, 2009.

DeYoung, B., Harris, R., Alheit, J., Beaugrand, G., Mantua, N., and Shannon, L.: Detecting regime shifts in the ocean: data considerations, Prog. Oceanogr., 60, 143-164, 2004.

Ebbesmeyer, C. C., Cayan, D. R., McLain, D. R., Nichols, F. H., Peterson, D. H., and Redmond, K. T.: 1976 step in the Pacific climate: forty environmental changes between 1968-75 and 19771984, Proc. 7th Ann. Pacific Climate Workshop, California Dept of Water Resources, Interagency Ecol. Stud. Prog. Report 26, 1991.

Froese, R., Zeller, D., Kleisner, K., and Pauly, D.: What catch data can tell us about the status of global fisheries, Mar. Biol., 159, 1283-1292, doi:10.1007/s00227-012-1909-6, 2012.

Garibaldi, L.: The FAO global capture production database: A sixdecade effort to catch the trend, Mar. Pol., 36, 760-768, 2012

Hátún, H., Payne, M. R., Beaugrand, G., Reid, P. C., Sandø, A. B., Drange, H., Hansen, B., Jacobsen, J. A., and Bloch, D.: Large bio-geographical shifts in the north-eastern Atlantic Ocean: From the subpolar gyre, via plankton, to blue whiting and pilot whales, Prog. Oceanogr., 80, 149-162, 2009.

Hilborn, R. and Branch, T. A.: Does catch reflect abundance?, Nature, 494, 303-306, 2013.

Huang, B., Hu, Z.-Z., Kinter III, J. L., Wu, Z., and Kumar, A.: Connection of stratospheric QBO with global atmospheric general circulation and tropical SST. Part I: Methodology and compos- ite life cycle, Clim. Dynam., 38, 1-23, doi:10.1007/s00382-0111250-7, 2012.

Lehodey, P., Alheit, J., Barange, M., Baumgartner, T., Beaugrand, G., Drinkwater, K., Fromentin, J.-M., Hare, S. R., Ottersen, G., Perry, R. I., Roy, C., van der Lingen, C. D., and Werner, F.: Climate Variability, Fish, and Fisheries, J. Climate, 19, 1009-1029, 2006.

King, J. R.: Report of study group on fisheries and ecosystem responses to recent regime shifts, PICES Scientific Report No. 28, 1-168, 2005.

Kodera, K.: Solar cycle modulation of the North Atlantic Oscillation: implications in the spatial structure of the NAO, Geophys. Res. Lett., 29, 1218, doi:10.1029/2001GL014557, 2002.

Mantua, N. J., Hare, S. R., Zhang, Y., Wallace, J. M., and Francis, R. C. : A Pacific Interdecadal Climate Oscillation with Impacts on Salmon Production, B. Am. Meteorol. Soc, 78, 1069-1079, 1997.

Matsuno, T.: Vertical propagation of stationary planetary wavesin the winter Northern Hemisphere, J. Atmos. Sci., 27, 871-883, 1970.

Matthes, K., Kuroda, Y., Kodera, K., and Langematz, U.: Transfer of the solar signal from the stratosphere to the troposphere: Northern winter, J. Geophys. Res., 111, D06108, doi:10.1029/2005JD006283, 2006.

Minobe, S.: A 50-70 year climatic oscillation over the North Pacific and North America, Geophys. Res. Lett., 24, 683-686, 1997.

Minobe, S.: Resonance in bidecadal and pentadecal climate oscillation over the North Pacific: Role in climatic regime shifts, Geophys. Res. Lett., 26, 855-858, 1999.

Overland, J., Rodionov, S., Minobe, S., and Bond, N.: North Pacific Regime shifts: Definitions, issues and recent transitions, Prog. Oceanogr., 77, 92-102, 2008.

Peterson, W. T., Hooff, R. C., Morgan, C. A., Hunter, K., Casillas, E., and Ferguson, J. W.: Ocean Conditions and Salmon Survival in the Northern California Current, Web Document, available at: http://www.nwfsc.noaa.gov/research/divisions/fed/ecosysrep. pdf (last access: 7 August 2009), 2006.

Powell, A. M. and Xu, J.: Abrupt climate regime shifts, their potential forcing and fisheries impacts, Atmos. Clim. Sci., 4, 33-47, 2011a.

Powell, A. M. and Xu, J.: Possible solar forcing of interannual and decadal stratospheric planetary wave variability in the Northern Hemisphere: an observational study, J. Atmos. Solar-Terrest. Phys., 73, 825-838, 2011 b.

Powell, A. M. and Xu, J.: The 1977 global regime shift: a discussion of its dynamics and impacts in the Eastern Pacific ecosystem, Atmos.-Ocean, 50, 421-436, doi:10.1080/07055900.2012.716023, 2012.

Powell, A. M. and Xu, J.: Regime Shifts of Global Marine Ecosystem with FAO Fishery Landing and Possible Physical Conditions, Int. J. Ecosyst., 3, 95-105, 2013.

Roy, C. and Reason, C. : ENSO related modulation of coastal upwelling in the eastern Atlantic, Prog. Oceanogr., 49, 245-255, 2001.

Shaw, T. A. and Perlwitz, J.: The Impact of Stratospheric Model Configuration on Planetary-Scale Waves in Northern Hemisphere Winter, J. Climate, 23, 3369-3389, 2010. 
Sugimoto, T., Kimura, S., and Tadokoro, K.: Impact of El Niño events and climate regime shift on living resources in the western North Pacific, Prog. Oceanogr., 49, 113-127, 2001.

Takasuka, A., Oozeki, Y., Kubota, H., and Lluch-Cota, S. E.: Contrasting spawning temperature optima: Why are anchovy and sardine regime shifts synchronous across the North Pacific?, Prog. Oceanogr., 77, 225-232, 2008.
Watson, R. and Pauly, D.: Systematic distortions in world fisheries catch trends, Nature, 414, 534-536, 2001. 